\title{
A Review of Asset Management Literature on Multi-Asset Systems
}

Keywords: Asset Management; Maintenance; Multi-unit; Multi-asset; Fleet; Portfolio; System Dependence; Multi-objective; Optimisation; Multi-criteria decision analysis

\begin{abstract}
This article gives an overview of the literature on asset management for multi-unit systems with an emphasis on two multi-asset categories: fleet (a system of homogeneous assets) and portfolio (a system of heterogeneous assets). As asset systems become more complicated, researchers have employed different terms to refer to their specific problems. With an objective to facilitate readers in searching conducive studies to their interests, this paper establishes a novel classification scheme for multi-unit systems in accordance with essential features such as diversity of assets and intervention options. Moreover, discerning differences in characteristics between cross-component and cross-asset interactions, we select three types of potential multi-component dependencies (performance, stochastic, and resource) and extend their notions to be applicable to multi-asset systems. The investigation into these dependencies enables the identification of problems that could exist in real industrial settings but are yet to be determined in academia. Ultimately, we delve into modelling approaches adopted by previous researchers. This comprehensive information allows us to offer the insights into the current trends in multi-asset maintenance. We expect that the output of this review paper will not only stress research gaps on multi-asset systems, but more importantly help systematise future studies on this aspect.
\end{abstract}




\section{Introduction}

As the industry deploys more technology and equipment for more services to satisfy consumer needs, the field of asset management has piqued interests of researchers from different disciplines. Since then, a multitude of studies in this field have been conducted, and the scope of the study has rapidly shifted from managing simple repair operations to optimising complex systems of multiple units. This focus has therefore led to the emergence of the term 'multi-unit system' in reliability engineering research.

With various interactions among components and assets in a system, optimisation modelling for maintenance has become immensely complicated. On one hand, these intricate interactions require substantial computational resources to deal with operations and maintenance problems. On the other hand, these characteristics also open up opportunity for devising policies that, compared to individual optimisation strategies, enhance the efficiency of the overall system.

Over the past years, researchers have put forward innovative solution methods to different types of multi-unit systems. Although these studies have greatly contributed to the body of knowledge and benefited the industry, adopters are required to put strenuous efforts to search for models that are appropriate to their specific problems. This is because different researchers have employed different expressions to refer to their systems.

Previous overview articles have made impressive strides in facilitating literature search for readers by categorising multi-unit systems according to their distinctive features. These classifications are generally based on types of dependence among members of a system. Dekker et al. [1] and Nicolai and Dekker [2] laid the foundations for the three main categories: economic, stochastic, and structural dependence. Structural dependence occurs when an intervention of a component requires that other components be intervened (either replaced or dismantled) at the same time. Stochastic dependence is referred to failure interactions among components. Economic dependence implies that a joint maintenance of several components either negatively or positively affects the overall expense.

Recently, Olde Keizer et al. [3] established the concept of resource dependence in which components in a system share common resources such as budget or spare parts. The authors also extended the definition of structural dependence by further classifying this into technical and performance dependence. A system is considered technically dependent when intervention activities for certain components are restricted by those of other components; the negligence of this dependence inevitably results in an infeasible maintenance strategy. Performance dependence is applied when an intervention activity, deterioration, and failure of a component affects the performance of other components and the overall system. This dependence is also referred to as system configuration in the survey by Wang and Chen [4]. The absence of performance dependence may lead to a feasible policy, but the optimality is not guaranteed. 
It is evident that previous literature review papers including [1], [2], [3], [4], [5], [6], and [7] emphasise on single-asset systems comprised of multiple components. However, to the best of our knowledge, a survey that compiles studies on systems of multiple assets has not been carried out. A need for multi-asset models emerges as intervention strategies for systems of multiple components are not applicable to systems of multiple assets. Two representative aspects that distinguish a multi-asset system from a multi-component system are the indistinct asset configuration and the effect of the system reliability on multiple stakeholders.

Since the configurational relationship among components in a multi-component system (e.g. series and parallel) is clearly defined, each component produces a distinct effect on the system output. In contrast, a multi-asset system such as a fleet of vehicles does not require that all assets work collectively in one location. Thus, the contribution of a dysfunctional asset on the output of a multi-asset system cannot be directly measured.

Another distinctive characteristic of a multi-asset system pertains to diverse effects of system reliability on multiple stakeholders. This characteristic is opposed to that of a multicomponent system of which the reliability chiefly affects the asset owner. A multi-asset system such as a portfolio of highway assets, which is large in scale as compared to a multicomponent system, not only produces an output for the asset owner but also provides direct services to multiple users.

Thus, it is a daunting task to choose an appropriate method for enhancing the reliability of the whole multi-asset system. Since the reliability of each asset could contribute differently to the system performance, traditional maintenance policies that consider each asset from a single dimension are not geared to supporting users to make well-informed decisions. To overcome this limitation, later researchers and practitioners have provided broader views on operating and maintaining physical assets and established the field of asset management.

The term asset management has been widely used since the International Organisation for Standardisation (ISO) established its definition in ISO 55000 [8]. Asset management is defined as an integrated activity to realise value from systems of assets. Compared to traditional maintenance engineering, despite the similar aim to enhance the system reliability, asset management extends its focus beyond improving system safety and reducing cost to delivering performance benefits to organisations and their stakeholders [9] [10]. Hence, in this integrated view, a decision on which asset and how it should be improved is determined by multiple output metrics, so that the utility of the system reliability is maximised.

The objective of this review paper is therefore to fill the literature gap by giving a review on comprehensive classes of multi-unit systems with an emphasis on multi-asset (fleet and portfolio) systems. To lay the foundations for our new classification, we compile different terms employed by previous researchers to refer to different multi-unit systems and examine their specific features (e.g. origin and usage, differences and similarities in intervention options, and asset diversity). Having identified patterned features of these terms, we classify 
multi-unit systems into three categories: multi-component, fleet, and portfolio. To explore interactions among assets, we draw three types of potential dependencies - namely performance, stochastic, and resource - and extend these notions in order that they are conducive to all categories. In addition, we collate studies that fall into these categories and identify possible dependencies that have not been examined in academia. Ultimately, for each multi-asset category, we scrutinise modelling approaches employed by previous scholars. Having delved into decision moments, objectives, types of assets, and techniques employed in these studies, we elaborate on the state-of-the-art and identify avenues for future research.

The remainder of this review paper is organised as follows. Section 2 provides the definitions of related terms and establishes distinct classifications of multi-unit and multiasset systems. In Section 3, we explore interactions among multiple assets within each of two multi-asset systems. Section 4 examines typical research problems in fleet and portfolio management and classifies these problems into seven decision classes. We also delve into methods for the enhancement of safety, reliability, and other performance measures of multiasset systems in Section 5. Representative studies are also gathered and exhibited according to solution method, decision class, and asset category. In Section 6, we highlight the key gaps in the literature to issue guidelines on potential research areas. Lastly, conclusions are drawn in Section 7.

\section{Classifications and definitions}

In this section, we compile previous literature that bolsters the classification and definition of multi-unit systems. We review the terms that were employed by previous researchers to refer to these systems. Having filtered out irrelevant contexts, we consider patterns in these terms and establish distinct categories of multi-unit systems. This section begins with the overview on the usage of the terms 'multi-unit' and 'multi-asset' systems. Subsequently, after providing our principal classification of these systems, we lay an emphasis on how the terms 'fleet' and 'portfolio' are adopted in asset management research. It is important to note that, in Section 2, we focus on the elementary characteristics of the systems adopted by previous researchers in order to help us primarily define these systems.

\subsection{Multi-unit system}

The concept of multi-unit asset management emerged when the industry began to step up the production and service with more equipment. With the huge impact of the asset reliability on the industry performance, practitioners and scholars therefore started to delve more deeply into how these assets can be fully exploited.

Early academics extended their single-unit models to deal with a two-unit system - the most fundamental scheme for a multi-unit system. Osaki and Asakura [11], Branson and Shah [12], Subramanian and Venkatakrishnan [13], and Kumar [14] pioneered the models for the 
'two-unit standby redundant system', which can be further categorised into warm-standby and cold-standby systems. As the models imply, the standby system consists of a primary system (an operating unit) and a secondary system (a backup unit). The major difference between warm-standby and cold-standby systems is the operation of the secondary system. The warmstandby unit runs in the background of the primary system. In contrast, the cold-backup system is called upon only when the primary system fails.

Afterwards, these maintenance models were implemented in complex systems with numerous units. The implementation amplified the scope of multi-unit systems to cover a wider range: from a group of multiple assets to an asset with multiple components. For example, Fard and Zheng [15] considered a policy that minimises the total maintenance cost for a multi-unit system which consists of different types of assets. However, employing the similar term, Park et al. [16] developed a block preventive maintenance policy for a multi-unit system, but this term was used to mention a system of multiple identical assets.

The use of the term 'multi-unit system' is even more divergent when researchers also applied this term to a single-asset system with various components (e.g. [17]). Khan and Gupta [18] were the early scholars who employed the term 'multi-component system' to indicate an asset with a number of components working in series or parallel connections. This definition has been adopted and become more prevalent among later researchers (e.g. [1], [19], and [20]). The review papers on multi-unit systems by Cho and Parlar [5] and Wang [6] also signalled the vast variety of multi-unit systems in the models they considered. Therefore, to establish a general principle for future multi-unit asset management research, we define the term 'multi-unit system' (see Fig. 1) as follows:

i. a system composed of multiple assets that share common characteristics or resources under the control of an organisation

or

ii. a single-asset system composed of multiple components operating together.

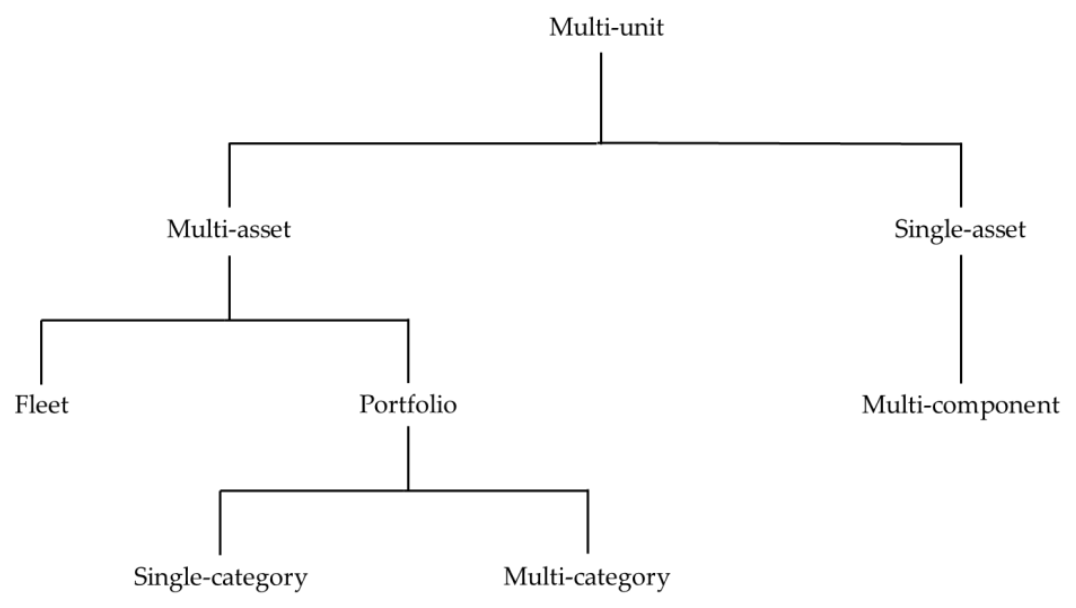

Fig. 1. Classification of multi-unit systems 
As aforementioned in Section 1, there exist a number of intelligently comprehensive literature review papers on 'multi-component' systems (i.e. [1], [5], [6], [7], and [3]). Hence, in our paper, we lay an emphasis on the review of 'multi-asset' systems.

\subsection{Multi-asset system}

The usage of the term 'multi-unit system' varies considerably. Hence, in following studies, researchers came up with different terms to refer to their specified systems. In the manufacturing engineering context, Trippi and Khumawala [21] examined an investment renewal problem for a system with various assets, initiating the term 'multi-asset system'. This term is also borrowed by later researchers to explain a system of serially dependent assets (e.g. [22] and [23]), that of independently operated homogeneous assets (e.g. [24]), that of heterogeneous assets (e.g. [25] and [26]), and other systems with multiple units.

In the control engineering context, $\mathrm{Alj}$ and Hauree [27] began to deal with a system with multiple units for a system comprised of a fixed number of identical elements working under the same conditions. In the study, the authors called this setting 'a system of m elements'. The similar expression is also adopted by other contributors such as Knessl [28], Dietz and Rosenshine [29], and Kenne and Boukas [30]. Latterly, Suryanarayan [31] also employed the term 'fleet' to refer to the system consisting of number of similar or identical machines.

Multi-asset maintenance problems have become even more complicated when an organisation has to cope with different types of assets at the same time. Zheng and Fard [32] proposed an opportunistic maintenance policy for a system consisting of different types of units and called this system a 'system of multi-type units'. Considering the similar context, recent researchers have also adopted the terms 'network' (e.g. [33]) and 'portfolio' (e.g. [34]) to indicate a system with heterogeneous assets.

As previously depicted in Fig. 1, in this paper, we further classify multi-asset systems into 'fleet' and 'portfolio' systems. Fundamental characteristics of these two categories are compared and summarised in Table 1 . These features will be discussed in details in the remainder of this section.

Table 1

Summary of fundamental features in two multi-asset categories

\begin{tabular}{lll}
\hline Feature & Fleet & Category \\
\hline No. of assets & Multiple & Portfolio \\
No. of components & Multiple & Multiple \\
Asset diversity & Homogeneous & Multiple \\
Asset category & Single & Single/Multiple \\
Intervention option & Equivalent among assets & Different among assets \\
Typical asset type & Vehicles & Infrastructure assets \\
\hline
\end{tabular}




\subsection{Fleet}

\subsubsection{Origin and usage}

The term 'fleet' was originally derived from the Saxon word 'fleot', which means a group of floating vessels [35]. Thus, in the academia, this term was traditionally used to mention a group of ships (e.g. [36], [37], and [38]). Subsequently, researchers in the field of reliability engineering extended the use of this term to cover a group of other vehicles. The classic examples include fleets of aircraft [39], buses [40], trains [41], and lorries [42]. As the manufacturing industry aggrandised, the term 'fleet' has correspondingly been used to mention other industrial systems in more recent studies. The epitome of the use of this term in an industrial context was demonstrated in a study by Wouters et al. [43] in which the authors compared different maintenance strategies for a fleet of power transformers. Other examples of modern applications are a fleet of lifts in a building [44] and that of machines in a factory [45].

\subsubsection{Diversity of assets and intervention options}

Although the diversity of assets is not explicitly mentioned in the majority of literature on fleet asset management, we can imply this aspect from the assumptions and models employed by researchers. There are slightly different variations of the assets comprised in a fleet.

The most typical type is the fleet of completely identical assets. For instance, Sarma and Rao [46] developed queuing models to estimate the availability of $N$ identical aircraft in a fleet. When considering a spare-part inventory policy for a fleet, Park [47] also referred to a group of $N$ identical parts. Other examples of the studies that point towards the same direction are [42], [48], [49], and [50].

Another form of fleet is a group of vehicles or machines that are not necessary identical but share mutual technical features and work under similar conditions. Sriram and Haghani [51] considered a fleet of aircraft as a pool from which any plane can be assigned to any origindestination (OD) route and maintained under the equivalent intervention level. Other advocates of this form of fleet are, for instance, [52], [53], and [54].

Despite subtle variations of fleets adopted, the vast majority of researchers concur in the homogeneity of intervention activities. Precisely, we can imply that, in a fleet, similar inspection and maintenance actions can be applied to any asset with similar conditions. As an illustration, in the models developed by Haghani and Shafahi [52], any maintenance bay owned by a bus operator can perform an equivalent inspection or maintenance activity on any bus in a fleet. Likewise, Godoy et al. [55] made an assumption that the critical spare parts in the stock can be applied to any asset in a fleet of haul trucks. 


\subsubsection{Definition}

Despite its various usage, the term 'fleet' employed by both industry and academia tends gravitate towards a set of patterned features. Hence, improving upon the explanations given by Monnin [53] and Rawat [54], we establish a modern definition of the term 'fleet' in asset management as follows:

i. In transportation systems, a fleet is a group of vehicles under the control of an organisation. The vehicles include motor vehicles (e.g. buses), railed vehicles (e.g. trains), watercraft (e.g. ships), and aircraft.

ii. In industrial systems, a fleet is a set of assets or machines which operate at one location such as a manufacturing plant.

iii. A fleet can be either

a. a group of identical assets

or

b. a group of assets that share similar technical features and work under the same operating conditions.

iv. Assets in a fleet share common maintenance facilities and resources.

v. Equivalent intervention options including inspection and maintenance actions (e.g. repair and replacement activities) can be applied to any asset in a fleet.

\subsubsection{Related terms}

With the definition and characteristics provided above, the following expressions can also be categorised as fleets:

- A system of $\mathrm{N}$ elements/machines (e.g. [27], [28], [29], [30], and [56])

- A multi-unit/multi-asset system of identical/homogeneous assets (e.g. [57], [58], [59], [60], and [61])

- A group of assets with identically and independently distributed (IID) inter-failure/ repair times (e.g. [62], [63], [64], and [65])

\subsection{Portfolio}

\subsubsection{Origin and usage}

Originally employed in financial sector, the term 'portfolio' has been used to describe a collection of different investments owned by an entity [66]. This term was subsequently introduced to the field of asset management by the ISO 55000:2014 Asset management Overview, principles and terminology [8]. The ISO standard generically defines an 'asset portfolio' as a group of assets established and assigned for managerial control purposes. Since its introduction, this expression has been widely acknowledged in the context of large assets, especially infrastructure assets. An early example of a physical asset portfolio is a group of buildings (e.g. [67] and [68]). Other typical examples are portfolios of nuclear reactors (e.g. [34]), bridges (e.g. [69], [70], and [71]), and plants (e.g. [72]). 


\subsubsection{Diversity of assets and intervention options}

Since the term 'asset portfolio' was introduced, asset management researchers have adopted it to identify systems in their studies. These contributors are apt to apply the term towards its original definition in finance industry, namely a group of heterogeneous assets. In the existing literature, there are different levels of asset diversity in a portfolio. In this subsection, we confer about two variations.

In the first variation, asset managers commonly construe an asset portfolio as a group of assets that belong the same category but that have different characteristics. In our study, we employ the term 'single-category portfolio' to refer to this system. We illustrate this point through a case study provided in the study by Morales-Torres et al. [73]. In the study, an organisation aimed at the effective prioritisation of safety investments on a portfolio of 27 dams. Although assets in the portfolio are of the same category (the reservoir), they are significantly different in terms of structure, size, construction year, and reservoir volume. Other proponents of this definition of portfolio are, for example, [67], [68], [69], and [74].

As for the second variation, some researchers pointed out that an organisation can have a problem in maintaining different types of assets and hence considered incorporating these diverse assets into one portfolio. In this paper, we establish the term 'multi-category portfolio' to explain this variation. Zhang and Wang [75] explained that the determinant of comprehensive assets owned by an organisation ensures the allocation of sufficient funding to sustain assets operational condition. Interesting examples of this form of portfolio are demonstrated in [76] and [77]. The former considered an approach to the management of a portfolio of various assets (i.e. buildings, facilities, and airfield pavements) under the control of the US Air Force. The latter developed strategies to maintain diverse portfolio of assets (i.e. cargos, sea walls, roads, navigation aids, and marine and berth structures) owned by the Newcastle Port Operation.

Apropos the intervention diversity, the heterogeneity of assets in a portfolio undoubtedly leads to different asset-specific intervention actions. McKoy [70] explained how the London Underground (LU) managed its portfolio of approximately 8,000 bridges. These bridges substantially differ in material profiles, structures, and functionalities (i.e. footbridges, overbridges, and underbridges). As a consequence, LU engineers had to apply specific assessments to definite groups of assets. For instance, while underbridges subject to rail vehicles loading had to be assessed for Railways London (RL) loading standard, the assessment of pedestrian footbridges was carried out to the $20 \mathrm{kN}$ concentrated loading standard.

\subsubsection{Definition}

In this study, we enhance the definition provided by the ISO 55000 [8] and define the term 'portfolio' in asset management as follows: 
i. An asset portfolio is a collection of assets under the control of an organisation.

ii. Assets in a portfolio do not necessarily operate at one location (e.g. buildings that are located in different places but that are owned and managed by an organisation).

iii. An asset portfolio is comprised of assets with different characteristics. Assets in a portfolio can be either:

a. Assets that fall into the same category but that have different features (e.g. a portfolio of heterogeneous bridges). We establish the term 'single-category portfolio' to refer to this type of portfolio.

or

b. Assets that fall into different categories (e.g. a portfolio of diverse assets managed by a city council). We establish the term 'multi-category portfolio' to refer to this type of portfolio.

iv. An intervention option that can be applied to an asset may not be applicable to another asset in the same portfolio.

\subsubsection{Related terms}

Based on the aforementioned definition, the following expressions also fall into the category of portfolios:

- A system of multi-type units (e.g. [32] and [78])

- A multi-unit/multi-asset system of heterogeneous assets (e.g. [79] and [80])

- A serially dependent production system of different machines (e.g. [22] and [23])

- Network of heterogeneous assets (e.g. [33] and [81])

\section{Dependencies in multi-unit systems}

This section intricately discusses interactions among assets in multi-unit systems with an emphasis on two multi-asset systems: fleet and portfolio. Having established the definitions of these systems and their related terms, we delve more deeply into the dependencies among components for multi-component systems and those among assets for multi-asset systems. Despite plentiful multi-component dependencies defined and discussed in previous literature, we select three types that are also conducive to multi-asset systems. That is, we discuss about the dependence among units in terms of performance, deterioration (stochastic), and resource. A brief summary of these dependencies is exhibited in Table 2. It is important to note that dependencies with * are those that may exist in industry, but that are yet to be determined in academia. 
Table 2

Summary of selected dependencies in three multi-unit categories

\begin{tabular}{|c|c|c|c|}
\hline \multirow{2}{*}{ Type of dependence } & \multicolumn{3}{|c|}{ Category } \\
\hline & Multi-component & Fleet & Portfolio \\
\hline $\begin{array}{l}\text { Performance } \\
\text { dependence }\end{array}$ & $\begin{array}{l}\text { - Series } \\
\text { - Parallel } \\
\text { - } k \text {-out-of- } N \\
\text { - Combination }\end{array}$ & $\begin{array}{l}\text { - Parallel } \\
\text { - } k \text {-out-of- } N\end{array}$ & $\begin{array}{l}\text { - Series } \\
\text { - Network }\end{array}$ \\
\hline $\begin{array}{l}\text { Stochastic } \\
\text { dependence }\end{array}$ & $\begin{array}{l}\text { - Failure induced effect } \\
\text { - Load sharing } \\
\text { - External factor }\end{array}$ & - Load sharing* & - Load sharing* \\
\hline $\begin{array}{l}\text { Resource } \\
\text { dependence }\end{array}$ & $\begin{array}{l}\text { - Workforce } \\
\text { - Maintenance facility } \\
\text { - Spare parts }\end{array}$ & $\begin{array}{l}\text { - Workforce } \\
\text { - Inspection tools } \\
\text { - Maintenance facility } \\
\text { - Spare parts }\end{array}$ & $\begin{array}{l}\text { - Budget } \\
\text { - Workforce* }\end{array}$ \\
\hline
\end{tabular}

\subsection{Performance dependence}

The concept of performance dependence, also known as system configuration, was mentioned in previous studies on multi-component systems (e.g. [3], [4], and [80]). This concept is generally used to explain the form of configuration among components for a multicomponent system. In this review paper, we extend the definition of performance dependence so that this term is also applicable to multi-asset systems. That is, we also take into account the performance relationship among assets for a multi-asset system. This relationship is deemed crucial as it helps determine the performance of the overall system. In multicomponent systems, performance dependencies that are apparent in practice include series (e.g. [82] and [83]), parallel (e.g. [84] and [85]), $k$-out-of-N (e.g. [86] and [87]), and any combinatorial configuration such as series-parallel (e.g. [88] and [89]). In a series system, a failure of a component results in a dysfunction of the entire system [90]. In contrast, parallel, $k$-out-of- $N$, and series-parallel emerge from the concept of traditional redundancy allocation problems of which the objective is to determine the number of redundant units in order to optimise a preset objective function [91]. The parallel configuration requires only one component for a system to operate properly [92], while the performance of a $k$-out-of- $N$ system depends upon a predefined condition. There are two types of traditional multi-component $k$ out-of- $N$ settings: $G$ and $F$. In the $G$ configuration, the whole system only functions if, out of the total $N$ components in the system, at least $k$ components are in their operational conditions [93]. Contrarily, in the F system, the system completely fails if at least $k$ component fails [94]. A literature survey emphasising on traditional redundancy allocation problems has been conducted by Mohamed et al. [91]. Comprehensive information on systems with performance dependent component can be found in the review paper by Olde Keizer et al. [3] and Wang and Chen [4]. 


\subsubsection{Fleet performance dependence}

As for fleet systems, limited research papers explicitly state the relationship among assets as researchers tend to focus on other aspects of the systems. Many studies made an assumption that performances of fleet assets are independent. For instance, we can imply from the policy proposed by Van Horenbeek et al. [48] that failures of assets in a fleet can be independently determined. In other words, an organisation incurs a downtime cost for each asset that fails, but the performance of the whole system is not affected by the failure of other fleet members.

Later contributors began to openly incorporate performance dependence in their research. Rasmekomen and Parlikad [95] investigated a multi-asset system in which $M$ identical non-critical machines operate in parallel before their output is fed to a critical machine. In this case, the relationship among assets is crucial as the authors inquired into how the performance of these parallel machines affects the performance of the critical machine and the system output.

Another typical performance relationship among assets in a fleet, albeit inexplicitly stated, is $k$-out-of- $N$. In this redundant system consisting of $N$ assets, a fleet depends on minimum $k$ assets to satisfy the total demand. Nonetheless, unlike the output of multicomponent $k$-out-of- $N$ system, fleet performance is not expressed in binary. That is, if fewer than $k$ assets are available, a fleet will not operate at its full capacity but will not completely fail. Rather, the system will encounter negative consequences in line with the number of unavailable assets less than $k$. In this study, we establish the term 'multi-asset $k$-out-of- $N$ ' to refer to this configuration type. To illustrate this point, we take a study by Moudani and MoraCamino [96] as an example. In their aircraft assignment and maintenance scheduling models, the authors established a constraint stipulating that every planned flight be covered by an available aircraft. This means that the number of operational aircraft must be at least equal to the number of planned flights $(k)$ and that the rest $(N-k)$ are allowed to undergo maintenance activities. Likewise for fleet of industrial assets, Liang et al. [45] also considered the minimum number of operational machines required when developing their queuing models. This configuration allows the user to estimate the level of spare machine inventory that minimises the downtime cost. Other studies that consider this relationship are [97] and [98].

\subsubsection{Portfolio performance dependence}

In portfolio asset management literature, researchers are apt to deal with problems at the organisational level such as risk management and budget allocation. In addition, due to its heterogeneity of assets, a portfolio system - especially a multi-category system - does not require these assets to work collectively. Hence, it may be reasonable to assume the performance independence in some multi-category portfolio systems. For example, Zhang and Wang [75] considered whole life cost models to identify maintenance strategy for each asset. After combining all the related figures, asset managers subsequently selected the most 
cost-effective strategy for budget planning. The framework implies that the performance of an asset does not affect the performance of the overall system.

Nevertheless, it may not be appropriate to make the same assumption for portfolio systems of which assets are operate in series or a network. Research studies undertaken by Stinson and Khumawala [22] and Semple and Sarkis [23] are the representatives of the serially dependent system. The authors considered a production system in which heterogeneous machines with different vintages operate collectively. In this setting, a failure of a machine greatly affects the production performance. As for assets operating in a network, there may arise a situation in which a failure of an asset affects the performance of the overall system. The problem of maintaining infrastructure assets can be considered the embodiment of this situation. Gokey et al. [99] stated that the performance of a bridge network could be measured by the volume of traffic. Hence, a failure of any bridge can result in a significant traffic disturbance of the overall system. Likewise, $\mathrm{Li}$ and Sinha [100] also incorporate a traffic impact into their optimisation model for highway asset maintenance project selection.

\subsection{Stochastic dependence}

In this review paper, we extend stochastic dependence in order that the expression is more conducive to all the multi-unit classes previously defined. Stochastic dependence, also known as failure interaction, has been intensively discussed in previous surveys. This term has been used to refer to a multi-component system of which the state of an asset can have an impact on the states of other components. The state considered can be age, failure state, degradation rate, or other measures [2]. To make this type of dependence pertinent to multiasset systems, we renew the definition of stochastic dependence as the effect of deterioration of a component on other components or that of an asset on other assets. The cause of stochastic dependence can be a failure-induced effect from other unit, workload sharing, or a similar external condition. The information on stochastic dependence on multi-component systems is comprehensively summarised in the surveys of Thomas [101], Nicolai and Dekker [2].

\subsubsection{Fleet stochastic dependence}

In fleet systems, as aforementioned, the majority of contributors do not take into consideration the operational interaction among assets. This performance independence therefore leads to the lack of deterioration interaction among assets under general circumstances. However, in some cases in which performance dependence is implied, there may also exist the stochastic dependence. It is apparent that the deterioration of an asset is neither induced by other fleet members nor caused by a mutual external effect. Hence, we can deduce that a system generally encounters a degradation interaction from load sharing. Specifically, when assets in a fleet operate in a $k$-out-of- $N$ system, the deterioration or failure of an asset requires other assets to cope with greater workload. This case is especially palpable in maintenance and service scheduling problems. For instance, the downtime of a bus could bring about additional workload for other buses in the same fleet in order to satisfy the daily 
service requirement. Nonetheless, there has been no report on academic research that incorporates this load-sharing dependence in a fleet setting.

\subsubsection{Portfolio stochastic dependence}

In some portfolio systems, assets are neither located within the same place nor required to operate together. Thus, it is sensible to assume that there is no stochastic dependence in some portfolio systems of this type. However, it may not be the case for a portfolio in which the assets operate in a neighbouring area. In this case, there probably exists a degradation interaction from load sharing. The epitome of this situation is the problem of managing a portfolio of neighbouring bridges that are under the responsibility of one city council. In this case, the failure of a bridge means that commuters have to take an alternative route via other bridges available. This leads to these nearby bridges receiving additional workload. Nonetheless, to the extent of our knowledge, there has been no report on such stochastic dependence in the among portfolio assets from previous literature. A study by Vacheyroux and Corotis [102] considered a case study that involves a portfolio of bridges under the control of the Mayor of Paris, but did not incorporate this stochastic dependence in their setting. In their numerical example, the authors selected only two bridges that are located far away from each other in their models in order to validate their assumption of the stochastic independence.

\subsection{Resource dependence}

Resource dependence occurs in a system in which members (components or assets) share common resources in their intervention actions. The shared resources can be financial (e.g. budget), human (e.g. workforce), and other physical resources (e.g. spare parts). This type of dependence is deemed crucial for multi-unit systems, especially fleet and portfolio systems; this is because the shared resources directly affect the asset management plan for intervention schedules, precipitating production and service interruption. However, the concept has not been elucidated in the previous literature. Thus, in this review paper, we investigate how these shared resources have been incorporated in the previous studies. In multi-component systems, previous researchers have taken into consideration workers (e.g. [103]), maintenance tools (e.g. [104]), and spare parts (e.g. [105]). Papers that involves resource dependence for multi-component systems have been extensively discussed in the study of Olde Keizer et al. [3].

\subsubsection{Fleet resource dependence}

As aforementioned, a fleet is comprised of either identical assets or assets that can be maintained with an equivalent intervention activity. Ergo, assets in this system are generally reliant on common resources. Previous studies indicate that fleet members may share resources on maintenance workforce, inspection tools, repair facilities, and spare parts. 
The study by Safaei et al. [97] aimed at optimising maintenance schedules for fleets of aircraft. In their mixed-integer mathematical programming model, the authors incorporated limited workforce resources, which include trades and technicians, as their main constraints. As for the inspection and repair facilities, Haghani and Shafahi [52] included finite inspection and maintenance lines (bays) as a constraint in their integer-programming formulation for maintenance scheduling. Likewise, Liang et al. [45] searched for an optimal policy for a scheduling problem in a repair shop that serves fleets of machines. These contributions demonstrate that machines in a fleet are critically dependent on the shared repair capacity.

Due to their homogeneity, members in a fleet can be repaired using similar spare parts. Park [47] was an early researcher who developed a model to estimate an optimal level of spare-part inventory for fleet maintenance. The part-sharing ability also leads to a very sophisticated approach to solve maintenance scheduling problem. Sheng and Prescott [106] delved into a cannibalisation policy for fleet maintenance. The cannibalisation strategy involves transferring a removable part from an asset to replace a failed part of another asset.

\subsubsection{Portfolio resource dependence}

Since portfolio maintenance problems are generally at the organisational level, the principal system constraint is therefore a budget. With various measures on different assets, decision makers are in need of a tool to help prioritise their inspection and maintenance tasks. These characteristics consequently lead to maintenance project selection and budget allocation problems. For instance, Bai et al. [107] considered a portfolio management problem in which a decision maker has to select an optimal set of projects to maintain bridges, pavements, and congestion assets under a constrained budget.

Due to the wide diversity of assets in a multi-category portfolio, it is unlikely that these assets could share technical resources. Therefore, to maintain their assets, various studies readily assume that intervention activities are independent. This assumption is reasonable as it conforms to the findings of previous papers that studied the impact of portfolio asset diversity on the decision to outsource maintenance services. A study by Anastasopoulos et al. [108] indicates that organisations are apt to outsource their maintenance projects mainly because it is not worthwhile to hire different specialised workers. The study also shows that outsourcing technical projects is beneficial to the organisations in terms of cost reduction, level of service improvement, and risk mitigation. Other related studies include [109], [110], and [111]. Nevertheless, this assumption can be unwarranted if asset owners provide in-house intervention services. Based on our experience, in many cases, organisations have common workers perform cross-asset maintenance projects. For instance, a rail company may have one repair team who is for bridge and other structure projects. This means that any two projects under the responsibility of this team cannot be carried out together in a considered horizon. 


\section{Decision classes}

This section delves into multi-asset research problems by examining types of decisions made in previous papers and offer a classification of decisions made in fleet and portfolio systems. Comprehensive decision classes (DCs) and their corresponding system categories are summarised in Table 3. Besides performing analyses on the classes of decisions that have not been firmly established, this paper will also provide knowledge sources for DCs that have been investigated by previous literature review papers.

Table 3

Summary of decision class and system category

\begin{tabular}{|c|c|c|c|}
\hline \multirow{2}{*}{ Decision class } & \multirow{2}{*}{ Fleet } & \multicolumn{2}{|c|}{ Portfolio } \\
\hline & & Single-category & Multi-category \\
\hline i. Intervention policy & $\mathrm{x}$ & $\mathrm{x}$ & \\
\hline ii. Intervention scheduling & $x$ & $x$ & \\
\hline iii. Spare parts management & $x$ & $x$ & \\
\hline iv. Equipment and asset selection & $x$ & $x$ & \\
\hline v. MR\&R project selection & & $x$ & $\mathrm{x}$ \\
\hline vi. Asset prioritisation & & $x$ & $x$ \\
\hline vii. Budget allocation & & $x$ & $x$ \\
\hline
\end{tabular}

\subsection{Intervention policy}

This DC focuses on identifying optimal maintenance plans for multi-asset systems of which the asset configuration is clearly defined. Intervention activities considered in this DC refer to inspection, repair, and replacement. Due to the definite effect of the reliability of each asset on the overall system performance, these problems could fit into existing system categories and therefore could be addressed by specific intervention policies. Hence, multiasset problems that belong to this DC can also be dealt with by existing multi-component models. As for systems in which multiple assets operate independently, an appropriate maintenance strategy to deal with each asset can be determined in isolation. Therefore, classic corrective maintenance (taking actions at asset breakdowns), preventive maintenance (taking actions at predefined intervals), and condition-based maintenance (taking actions based on information collected) can be applied to these asset-independent systems. Details of the application of these traditional policies can be found in the literature survey by Wang [6].

However, the implementation of these policies may not lead to a feasible or an optimal solution for systems in which asset dependencies exist. Unlike an independent single machine, a multi-unit system encounters different consequences of the different number of asset dysfunctions. Negative effects on the system performance and reliability substantial especially in the equipment replacement problem as high downtime is associated. Moreover, devising a policy for each asset in isolation could lead to an infeasible strategy as the aggregate cost is likely to violate budget and resource constraints. Hence, previous researchers have incorporated performance and resource [112] dependencies into problems in this DC. The 
equipment replacement problem with resource dependence is more complex in a portfolio than in a fleet because different cost and deterioration functions are associated [113], [114].

Moreover, previous researchers have developed tailored intervention policies to exploit the multiplicity characteristic of multi-asset systems. Prominent maintenance strategies include group maintenance, block replacement, cannibalisation, opportunistic maintenance, and selective maintenance policies. In both group maintenance and block replacement policies, assets are replaced at periodic interval, but the latter has more flexibility as it also allows an individual asset to be replaced upon its failure. Cannibalisation policy enables a functional component in a failed asset to become a spare part for other assets in order to maximise the number of operational assets in the system. Opportunistic maintenance policy utilises the system downtime due to an asset failure to perform maintenance activities on other assets that are yet to fail with an objective to reduce set-up cost and prevent future failure. Recent selective maintenance policy is a variation of a condition-based maintenance which customises a maintenance policy of each asset according to its actual condition and the mission profile of the system. Studies on maintenance models for systems with dependent units have been systematically organised in literature review papers by Cho and Parlar [5], Olde Keizer et al. [3], and Cao et al. [115]. Specific studies on equipment replacement analysis for multi-asset systems have been compiled in the literature survey by Hartman and Tan [116].

\subsection{Intervention scheduling}

In multi-asset systems, intervention scheduling pertains to the determination of the optimal arrangement for the downtime of multiple assets that need to be preventively maintained in order that the impact on the production and operation is minimised. Intervention scheduling problems generally emerge from two grounds. Firstly, there are insufficient maintenance resources or facilities to serve assets in a fleet. Secondly, multi-asset systems necessitate that a specific number of assets be in operational conditions so that the demand is satisfied. Therefore, problems in this DC usually consider the joint optimisation of preventive maintenance and operation/production schedules. Since these problems are resource-centric, they generally belong to fleet and single-category portfolio systems. These problems are generally considered in the context of industrial systems, infrastructure assets and vehicles.

Joint maintenance and job scheduling problems began to be investigated when researchers became aware that machine availability assumptions made in production planning models were flawed. Lee [117] was an early scholar who endeavoured to remove this assumption by integrating machine breakdown and preventive maintenance into a scheduling model. Traditional studies considered only a limited number of objectives - for instance, to minimise the sum of completion times (e.g. [118] and [119]) and to minimise the makespan (e.g. [120] and [121]) - in their formulation. In these models, downtime due to maintenance and system failure are generally formulated as a constraint. A review of applications of these classic models in the context of traditional multi-machine systems were 
neatly conducted by Schmidt [122]. Modern studies highlighted the importance of intervention activities and started to incorporate costs incurred by these activities as an objective in their models. Examples of interesting papers in this context are [123], [124], [125], and [126].

In larger systems such as fleets or portfolios of infrastructure assets, there is a need for more criteria to be incorporated in a maintenance scheduling model. In these systems, an effective maintenance plan is deemed crucial because system downtime could lead to major economic issues that exert effects on multiple stakeholders. Maintenance planning issues in power plants and farms that have profound economic consequences are considered representative problems in this aspect. These studies typically take into consideration a wider range of reliability criteria such as the maximisation of net power reserves (e.g. [127], [128], and [129]) and the minimisation of the sum of the squares of the reserves (SSR) (e.g. [130], [131], and [132]). Moreover, multiple economic criteria are also considered simultaneously; these include the minimisation of maintenance cost, start-up cost, opportunity cost, and compensation cost (e.g. [133], [134], [135] and [136]). Comprehensive lists of studies on maintenance scheduling problems in electricity industry can be found in an extensive review by Froger et al. [137], while those on preventive maintenance scheduling issues for railways assets can be further explored in a survey by Soh et al. [138].

Intervention scheduling problems for vehicle fleets and portfolios are even more complicated. Unlike industrial machines or infrastructure assets, vehicles do not generally operate at a single location. This characteristic makes it difficult to identify the relationship between the downtime of a single vehicle and the overall system performance, thereby leading to a major challenge in determining an appropriate performance measure for fleet maintenance management. Moreover, it is not straightforward to devise a definitive fleet maintenance scheduling plan because this process generally involves other components such as network route design, allocation of vehicles to trips, and assignment of drivers [51] . Thus, besides traditional reliability measures such as mean time between failures and mean time to repair (e.g. [139] and [140]), various functional measures including transport operation and safety indicators were also employed by researchers to assess the overall fleet performance. Previous studies (e.g. [141], [142], and [143]) used the proportion of actual to planned tasks to measure the performance of the system. Other interesting transport indicators include fleet utilisation rate (e.g. [52]) and fleet energy efficiency (e.g. [144]), while the widely used measures for safety and emission are accident rate (e.g. [145]) and fleet roadworthiness (e.g. [146]). An extensive list of fleet performance measures employed in previous vehicle maintenance scheduling studies can be found in the study by Vujanovic et al. [147].

\subsection{Spare parts management}

The problem on asset spare parts management generally pertains to stock and inventory management because asset managers are required to strike a balance among holding cost, ordering cost, and system downtime cost. On one hand, high holding cost is incurred if an 
organisation stores excessive spare parts. On the other hand, an organisation may suffer from high ordering cost when it places too frequent orders, and from high downtime cost when there are insufficient spare parts to maintain its assets. Since common spare parts are only shared by assets in the similar category, the problem of spare parts management is exclusive to fleets and single-category portfolios.

Due to the asset homogeneity in a fleet system, an asset manager can consider only a few criteria to draw up a spare parts inventory strategy for asset fleets. This characteristic enables a decision on replenishing spare parts to be made jointly with other maintenance decisions. For example, Van Horenbeek et al. [48] developed models to optimally devise a joint policy of asset replacement interval and spare parts inventory. Similarly, Godoy et al. [55] provided a framework to integrate critical spares stock-holding strategy with a preventive maintenance policy. Sheng and Lescott [106] conducted a state-of-the-art research on fleet spare parts maintenance by incorporating a cannibalisation policy into their models. This novel policy allows an unserviceable part of an asset to be replaced by a serviceable part from another asset.

Assets in a single-portfolio are diverse, making the management of spare parts even more complex, especially when assets are comprised of a large number of components. This diversity requires a company to deal with a massive number of items in the inventory. Thus, to devise an efficient inventory policy for a system, many researchers and practitioners have proposed different approaches to classify these items using different criteria. These classifications not only allow common spare parts to be clustered, but also enable asset managers to develop inventory strategies in accordance with the criticality and demand of each class. Examples of prevalent classification schemes are multi-criteria ABC classification and demand-based categorisation [148]. Comprehensive literature reviews on spare parts management that include problems on both multi-asset categories have been conducted by numerous researchers. Recent surveys on this aspect are [148], [149], [150], and [151].

\subsection{Equipment and asset selection}

Equipment and asset selection involves the identification and acquisition of equipment that is appropriate to an asset system. This DC has been a vital issue in asset management research because the output of a selection process directly affects the maintainability of the system. This means that a proper selection and use of an asset is inextricably linked to the productivity, product and service quality, intervention cost, and reliability of a system. Equipment selection problems with an emphasis on single-unit systems have been addressed by previous researchers. Early studies considered only cost-related factors such as operating and equipment purchase costs (e.g. [152] and [153]). Later contributors incorporated aspects regarding performance and reliability (e.g. [154]) and employed multi-criteria decision analysis methods to strike a balance among different metrics. However, to the best of our knowledge, research on equipment and asset selection for multi-asset systems is still very limited. Moreover, existing studies deal with only one objective and readily assume asset 
independence in their models. Azam et al. [155] formulated a helicopter fleet selection model with a single objective to maximise the mission reliability, while Sperstad [156] developed a decision support tool that optimises operation and maintenance costs using a case study of vessel fleet selection in offshore wind farms.

\subsection{Maintenance, repair, and rehabilitation project selection}

Maintenance, repair, and rehabilitation project (MR\&R) project selection problems arise from the limited allowance for maintaining multiple assets in a system. Therefore, asset managers have to select a set of options that yield the maximum benefit for the organisation and its stakeholders. Unlike problems on intervention management, the MR\&R management problem is exclusive to portfolios as more criteria are applied to the systems. The need for more criteria is due to both the effect of large-scale systems on multiple stakeholders and the requirement of different metrics for the different types of assets. Main challenges posed by problems in this class are that the criteria are generally conflicting and that some of them are unquantifiable. Thus, decisions on portfolio MR\&R planning are often based on subjective judgment. To address the problem, previous researchers endeavoured to develop systematic decision support frameworks that involve multiple objectives. The typical asset category considered in this DC is a portfolio of transport and infrastructure assets.

In single-category portfolios, an organisation can consider only common criteria that can be applied to any asset in the system. Selih et al. [157] were early scholars to propose a systematic approach for managing highway infrastructure assets. Using a case study of overpass rehabilitation project selection, the study used common functional performance and cost metrics and applied a pair-wise method to prioritise these them. Another example of literature that considers common value metrics in single-category portfolio systems is a study by Srinivasan and Parlikad [71]. To help asset managers prioritise their bridge maintenance activities, the authors take into account five different factors (safety, service, cost, sustainability, and reputation) that influence values perceived by stakeholders. Other approaches to MR\&R project selection for single-category portfolios can be found in [158], [159], [160], [161] [162] and [163].

As for multi-category portfolios, it is apparent that common performance metrics are not compatible with assets from different categories. Therefore, the problem on MR\&R project prioritisation for these portfolios is more complicated according to more criteria associated. In a study by Bai et al. [107], besides different performance indices employed to evaluate three types of assets, common measures such as travel speed and crash rate are also adopted. These common measures can be applied to any assets in the portfolio and can help reflect impacts of these performances on road users. Falls et al. [164] also investigated how performances of various assets can be combined by establishing the concept of Asset Service Index (ASI). The ASI was defined as the deviation of actual service performance of an asset from its expected performance and therefore can be applied to different assets in a portfolio. Other interesting 
papers on multi-category portfolios in this DC can be further explored in [100], [165], [166], [167], and [168].

\subsection{Asset prioritisation}

An organisation is in need of a framework for prioritising assets in a system when their performances contribute unequally to the overall system value. Under limited resource, asset managers have to give priority to assets that are more critical to the system, so that appropriate intervention activities can be performed accordingly. Hence, this problem class entails the incorporation of criticality analysis into a decision support framework. The concept of criticality analysis has been employed by previous researchers to establish the relationship between asset reliability and system performance. Previous researchers and practitioners provided slightly different definitions of criticality in both system design and maintenance, but are apt to concur on applying quantitative measures to severity of failure and the risk or frequency of occurrence (e.g. [169], [170], and [171]).

Crespo Marquez et al. [172] performed a criticality analysis with an emphasis on maintenance management. The authors stressed the need for asset prioritisation and developed a model that establishes a hierarchy of assets in accordance with their associated risks (frequency levels) and impacts on business objectives (functional loss severity). The authors employed a case study of heterogeneous assets in a power plant to validate their model. In a recent study by Adams et al. [173], the authors considered a portfolio system in which the risk profile and the consequence of asset failure change over time. The study proposed a dynamic criticality-based model to which the inputs are updated as the operating environment changes. Other applications of the criticality analysis in asset prioritisation can be further explored in [174], [175], [176], [177], and [178]. Comprehensive techniques for prioritising assets for maintenance purposes have been succinctly summarised in [179].

\subsection{Budget allocation}

As previously stated, although assets in a portfolio may require different costs, intervention options, and performance metrics, they all operate in a single system and compete for budget allocations. Due to substantial impacts of decisions made in this class on the organisation's performance and profitability, many researchers and practitioners have presented different frameworks to support the decision-making for senior managers. As with the challenges identified in the MR\&R project selection class, conflicts in objectives among different assets and dissimilar needs of stakeholders also exist in this class. However, the budget allocation problem is more complicated as the relationship between the budget allocated and the improvement in asset performance and reliability is not explicit. Therefore, some researchers made an assumption on the improvement level while some also developed budget allocation models upon their MR\&R project selection frameworks.

In single-category portfolios, assets in the same category are associated with common value drivers and therefore requires only a few performance metrics. For instance, Chan et al. [180] investigated different pavements and proposed to make budget allocation decisions based on pavement damage index (PDI) - the index that can be applied to any asset in this 
pavement portfolio. Likewise, Mills et al. [67] made suggestions on the amount of income that the National Health Service Trusts should reinvest to maintain their building portfolio. The authors made their suggestions using critical backlog levels as a criterion. Other studies addressing the single-category portfolio problem in this class are [68], [81], and [181].

The problem belonging to this DC is typical for multi-category portfolios because budget is the main resource shared among diverse assets. In this system, the difficulty of investment decision-making is that multiple performance measures are required to capture the effect of budget allocated to each type of asset. To deal with this diversity, an effective strategy is to develop a systematic framework for combined multiple measures into a single function. An alternative strategy is to produce set of solutions and leave the final decision to be made by the management. A representative study that considers different measures to evaluate performance of diverse index can be found in Fwa and Farhan [182]. In their study, pavement condition index, bridge health index, and remaining service life were adopted evaluate performances of pavements, bridges, and appurtenances respectively. The authors employed a two-stage optimisation framework of which the second stage performed a crossasset trade-off analysis. Gharaibeh et al. [183] also applied an independent single-attribute utility (SAU) function to determine the performance of each asset category. Multiple SAU functions were subsequently combined into a multi-attribute utility function to support the decision-making. Other related studies on this aspect include [184], [185], [186], [187].

\section{Solution methods}

This section investigates techniques employed by previous researchers to derive a solution for their problems. Details including advantages and disadvantages of various optimisation and multi-criteria decision analysis (MCDA) methods are provided in this section. To elucidate the link between these methods and other aspects of multi-asset systems, this paper classifies and summarises representative references according to solution method, decision class, and asset category in Table $4-8$.

\subsection{Optimisation methods}

In this study, optimisation methods are organised into three classes as depicted in Fig. 2. The first two classes consider methods to solve single-objective optimisation models. The classification of these methods into deterministic and stochastic methods is based on the work by Yang [188]. Finally, algorithms that are employed to address multi-objective problems are discussed in the third class. In Table $4-6$, a reference is exhibited twice if multiple methods are employed in the study. It is also noteworthy that references belonging to the first two classes but considering multiple objectives are those that covert these criteria into one before deriving the optimal solution or those that deploy a multi-step approach. The conversion of multiple criteria will be further discussed in the next sub-section. 


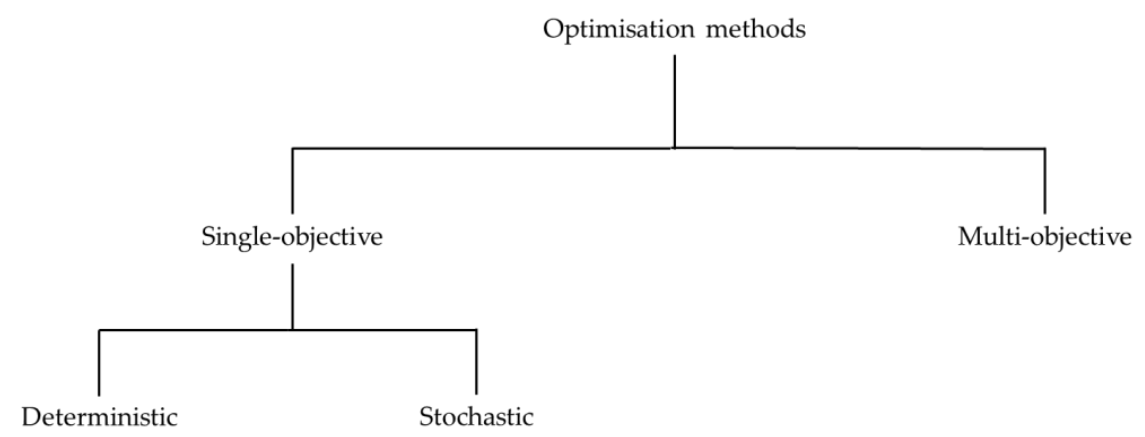

Fig. 2. Classification of optimisation methods

Table 4

Summary of references on deterministic optimisation methods

\begin{tabular}{|c|c|c|c|c|}
\hline Decision class & Reference & Asset category & Objective(s) & Optimisation method(s) \\
\hline \multirow[t]{2}{*}{$\mathrm{i}$} & {$[22]$} & SP: Production machines & Maintenance cost (min) & MIP \\
\hline & [23] & SP: Production machines & Maintenance cost (min) & LP \\
\hline \multirow[t]{13}{*}{ ii } & [189] & F: Manufacturing tools & Operating profit (max) & MIP \\
\hline & [190] & F: Manufacturing tools & Asset availability (max) & MIP \\
\hline & & & Maintenance cost (min) & \\
\hline & [51] & F: Aircraft & Maintenance utility (max) & LP \\
\hline & [97] & F: Aircraft & System availability (max) & MIP \\
\hline & {$[52]$} & F: Buses & Maintenance cost (min) & MIP \\
\hline & [191] & F: Trucks & Maintenance cost (min) & MIP \\
\hline & [192] & F: Power generators & Operating cost (min) & MIP \\
\hline & [193] & F: Power generators & Maintenance cost (min) & MIP \\
\hline & [194] & F: Power generators & Operating profit (max) & MIP \\
\hline & [195] & F: Power generators & Operating cost (min) & $\mathrm{LP}$ \\
\hline & [196] & F: Power generators & System reliability (max) & QP \\
\hline & [197] & SP: Bridges & Maintenance cost (min) & MIP \\
\hline \multirow[t]{4}{*}{$\mathrm{v}$} & [198] & SP: Bridges & Condition index (max) & MIP \\
\hline & & & Maintenance cost (min) & \\
\hline & [199] & SP: Pavements & Maintenance effect (max) & MIP \\
\hline & & & Maintenance cost (min) & \\
\hline
\end{tabular}


Table 5

Summary of references on stochastic optimisation methods

\begin{tabular}{|c|c|c|c|c|}
\hline Decision class & Reference & Asset category & Objective(s) & Optimisation method(s) \\
\hline \multirow[t]{27}{*}{ ii } & [104] & F: Production machines & System risk (min) & GA \\
\hline & [123] & F: Production machines & Makespan (min) & GA \\
\hline & & & Maximal workload (min) & \\
\hline & & & Total workload (min) & \\
\hline & [200] & F: Production machines & Makespan (min) & GA \\
\hline & [201] & F: Production machines & Operating profit (max) & GA \\
\hline & [51] & F: Aircraft & Maintenance utility (max) & Not specified \\
\hline & [96] & F: Aircraft & Operating cost (min) & Not specified \\
\hline & [202] & F: Aircraft & Makespan (min) & GA \\
\hline & {$[52]$} & F: Buses & Maintenance cost (min) & Not specified \\
\hline & [203] & F: Ships & System availability (max) & GA \\
\hline & [130] & F: Power generators & SSR (min) & GA, SA \\
\hline & [131] & F: Power generators & $\mathrm{SSR}(\min )$ & PSO \\
\hline & & & Intervention cost (min) & \\
\hline & [204] & F: Power generators & SSR (min) & SA \\
\hline & [205] & F: Power generators & Operating cost (min) & SA \\
\hline & [206] & F: Power generators & Operating cost (min) & GA, SA, TS \\
\hline & [207] & F: Power generators & SSR (min) & GA \\
\hline & [208] & F: Power generators & Intervention cost (min) & GA, PSO \\
\hline & [209] & F: Power generators & SSR (min) & $\mathrm{PSO}$ \\
\hline & & & Operational impact (min) & \\
\hline & [210] & F: Power generators & Operating cost (min) & SA \\
\hline & [211] & F: Power generators & Operating cost (min) & TS \\
\hline & [212] & F: Thermal units & Operating cost (min) & GA, SA, TS \\
\hline & [213] & F: Thermal units & Operating cost (min) & GA, SA \\
\hline & [214] & F: Refinery vessels & System availability (max) & GA \\
\hline & & & Maintenance cost (min) & \\
\hline \multirow[t]{8}{*}{ iii } & [215] & F: Production machines & Inventory cost (min) & GA \\
\hline & [216] & F: Production machines & Spare part inventory (min) & Not specified \\
\hline & [217] & F: Production machines & Inventory cost (min) & GA \\
\hline & & & Operating cost (min) & \\
\hline & [218] & F: Not specified & Inventory cost (min) & GA \\
\hline & & & Maintenance cost (min) & \\
\hline & [219] & F: Not specified & Operating profit (max) & GA \\
\hline & & & Total spares volume (max) & \\
\hline \multirow[t]{5}{*}{$\mathrm{v}$} & [220] & SP: Pavements & Network performance (max) & GA \\
\hline & [221] & SP: Rail tracks & Operational impact (min) & Not specified \\
\hline & & & Maintenance cost (min) & \\
\hline & [222] & MP: Railway assets & Maintenance cost (min) & Not specified \\
\hline & & & Possession cost (min) & \\
\hline \multirow[t]{3}{*}{ vii } & [180] & SP: Pavements & Network performance (max) & GA \\
\hline & & & No. of assets repaired (max) & \\
\hline & & & Maintenance cost (min) & \\
\hline
\end{tabular}

GA = Genetic algorithm, SA = Simulated annealing, TS = Tabu search, PSO = Particle swarm optimisation 
Table 6

Summary of references on multi-objective optimisation methods

\begin{tabular}{|c|c|c|c|c|}
\hline Decision class & Reference & Asset category & Objective(s) & Optimisation method(s) \\
\hline \multirow[t]{17}{*}{ ii } & [125] & F: Production machines & System unavailability (min) & NSGA-II, SPEA-2 \\
\hline & & & Makespan (min) & \\
\hline & [223] & F: Production machines & System unavailability (min) & NSGA-II \\
\hline & & & Makespan (min) & \\
\hline & [224] & F: Water pumps & Maximum power peak (min) & SPEA \\
\hline & & & Maintenance cost (min) & \\
\hline & & & Electric energy cost (min) & \\
\hline & & & Reservoir level variation (min) & \\
\hline & [225] & F: Power generators & System reliability (max) & NGSA-II \\
\hline & & & Uniform risk (min) & \\
\hline & & & Profit loss (min) & \\
\hline & [136] & F: Wind turbines & SSR (max) & NSGA-II \\
\hline & & & Maintenance cost (min) & \\
\hline & [226] & SP: Ship borne machinery & System reliability (max) & NSGA-II \\
\hline & & & Maintenance cost (min) & \\
\hline & [227] & SP: Bridges & Performance index (max) & MOGA \\
\hline & & & Maintenance cost (min) & \\
\hline \multirow[t]{23}{*}{$\mathrm{v}$} & [228] & SP: Bridges & Condition index (max) & MOGA \\
\hline & & & Safety index (max) & \\
\hline & & & Maintenance cost (min) & \\
\hline & [229] & SP: Bridges & Condition index (max) & MOGA \\
\hline & & & Maintenance cost (min) & \\
\hline & [230] & SP: Bridges & Condition index (max) & MOGA \\
\hline & & & Safety index (max) & \\
\hline & & & Maintenance cost (min) & \\
\hline & [231] & SP: Bridges & Condition index (max) & MOGA \\
\hline & [163] & SP: Pavements & Performance index (max) & MOGA \\
\hline & & & Maintenance cost (min) & \\
\hline & & & Environmental impact (min) & \\
\hline & [232] & SP: Pavements & Work production (max) & MOGA \\
\hline & & & Performance index (max) & \\
\hline & & & Maintenance cost (min) & \\
\hline & [233] & SP: Pavements & Condition index (max) & MOGA \\
\hline & & & Maintenance cost (min) & \\
\hline & [107] & MP: Transport assets & Condition index (max) & NSGA-II \\
\hline & & & Performance index (max) & \\
\hline & & & Safety index (max) & \\
\hline & [167] & MP: Transport assets & Condition index (max) & NSGA-II \\
\hline & & & Performance index (max) & \\
\hline & & & Safety indices (max) & \\
\hline \multirow[t]{2}{*}{ vii } & [182] & MP: Highway assets & Condition index (max) & MOGA \\
\hline & & & Maintenance cost (min) & \\
\hline
\end{tabular}

MOGA = Multi-objective genetic algorithm (not specified), NSGA-II = Non-dominated genetic algorithm-II, SPEA $(-2)=$ Strength Pareto evolutionary algorithm(-2) 


\subsubsection{Deterministic optimisation methods}

Representative studies applying deterministic optimisation methods are summarised in Table 4. Classic deterministic optimisation algorithms have been employed by researchers who formulated their problems under mathematical programming frameworks. These frameworks generally concern the optimal task assignment under conflicting constraints. Therefore, mathematical programming techniques including Linear Programming (LP), Quadratic Programming (QP), and Mixed-Integer Programming (MIP) have been employed in previous studies particularly on intervention scheduling problems (DC ii).

A major advantage of the application of deterministic algorithms is that these techniques are the most used branch in operational research and therefore are firmly established. Various algorithms such as simplex method, criss-cross algorithm, affine scaling, branch and bound, branch and cut, and cutting-plane methods have been developed and are currently supported by high performance software. Hence, in most cases, the global optimal solution is guaranteed. Nonetheless, these applications possess a major drawback - the inflexibility. These algorithms are fully effective if the problem can be formulated in a specific format. For instance, all the objective function and the constraints must be linear in LP, while QP only allows objective function to be quadratic with linear constraints. Therefore, these algorithms may not be suitable for multi-asset systems that require complex functions or have combinatorial nature. This limitation allows users to deal with only simple objective functions in their studies, as shown in Table 4.

\subsubsection{Stochastic optimisation methods}

Asset management studies applying stochastic methods are listed in Table 5. Stochastic methods, also known as heuristic and metaheuristic methods (H\&M), enable the user to overcome complexity and non-linearity of objective functions and constraints. Since difficult combinatorial optimisation problems cannot be formulated in a form that is solvable by deterministic algorithms, a feasible strategy to search for the best solution through trial and error. H\&M algorithms are based on this idea with an objective to find an acceptable solution in a reasonable time. By selectively examining solutions, H\&M algorithms have shown significant computational benefits over traditional exhaustive search, which examines every single solution in the feasible space. Thus, over the past decades, H\&M algorithms such as genetic algorithm (GA), simulated annealing (SA), particle swarm optimisation (PSO), and Tabu search (TS) have been widely used in asset management research.

GAs are the most widely used H\&M method in multi-asset optimisation problems. Inspired by the theory of natural evolution, Holland [234] was the first to develop GAs in his study on adaptive and artificial systems. The basic procedure of GAs involves the encoding of objectives as arrays of character strings and the manipulation operations of strings (crossover and recombination, mutation, and selection). The algorithm terminates these iterative operations when predefined stopping criteria are met. Besides the ability to deal with complex problems as with other H\&M methods, parallelism is another distinct advantage of 
GAs. Since multiple offsprings in a population are independent, the population can diversify the search in different directions at the same time. Despite their practicality and flexibility, GAs has a major drawback as the algorithms are sensitive to parameters. An inappropriate set of parameters may disable the convergence of solution, leading to impractical results. Another disadvantage of GAs is that a larger population size is required to generate more quality solutions to complex problems; this leads to a higher computational cost and longer run time.

SA is a random search technique that replicates the annealing process in metallurgy. Since its introduction by Kirkpatrick el al. [235], SA has been employed by various researchers in searching for solutions in problems with multiple local optima. The basic logic of SA is to conduct random search that not only accepts improving solution but also keeps nonimproving solution with a prescribed probability. This characteristic leads to a significant advantage of SA - the ability to escape local optima. Another advantage of SA is that the computational cost does not increase significantly if the problem becomes more complex. However, SA also possesses the similar drawback to GA in that it is sensitive to parameters (temperature and cooling rate).

Developed by Kennedy and Eberhart [236], PSO is an algorithm that is based on swarm behaviour of animals that evolve by information exchange. Since PSO is a population-based algorithm, it shares certain similarities with GAs. The movement of a swarming particle consists of two components, deterministic and stochastic, that move in the search space. Despite its inclination to move randomly, each particle is also influenced by the current best particle and the best location in history. A profound difference between PSO and GAs is that PSO employs the real-number randomness and communication among particles instead of mutation and crossover operators in GA. The simplicity of calculation enables the algorithm to carry out the search by the speed of particles and offers the main advantage in lower computational cost and faster run time.

TS is a local search-based developed by Glover [237]. The main element of TS is the use of adaptive memory - Tabu lists - to create search behaviours that avoid recently visited space. In TS, a sample of the solution neighbourhood is examined. Subsequently, the best element from the sample that does not belong to Tabu lists is selected. This essence strikes the balance between the solution quality and computational cost, encouraging search for optimal solution in a more efficient way.

It is apparent that the main advantage of H\&M methods is the flexibility that enables them to address complex optimisation problems. As shown in Table 5, stochastic methods are extensively used in DC ii as with deterministic methods, but the major difference is the complexity in objective functions and constraints. An example of the complexity is the inclusion of sum of squares of the net power reserve (SSR) as an objective function in power generator maintenance scheduling problem (e.g. [130], [131], [204], [207], and [209]). The minimisation of SSR implies the maximisation of fleet system reliability. Moreover, H\&M methods also allow the incorporation of comprehensive cost functions that consist of more components (e.g. [214], [217], and [222]), thereby making the problem formulation more 
pragmatic. A representative example of this aspect is the cognisance of complex inventory and operating cost functions in spare parts management problems (DC iii). Despite the flexibility of H\&M methods, a distinct drawback is that the global optimal solution is not guaranteed due to the randomness in search algorithms. Moreover, it is difficult to indicate which algorithm is effective to a specific type of problem. More importantly, it is also too complicated to investigate the cause of effectiveness or ineffectiveness of an algorithm to a problem.

\subsubsection{Multi-objective optimisation methods}

To address multi-asset problems, an organisation has to consider of different viewpoints from various stakeholders. This consideration leads to the incorporation of multiple objectives into the decision making process. Asset management researchers have developed their models under various multi-objective optimisation (MOO) frameworks, as shown in Table 6. Since it is cogent that only one objective can be maximised or minimised at a time, the concept of Pareto efficiency [238] has been adopted. A solution is considered Pareto optimal if an improvement on one objective cannot be made without negatively affecting at least one of other objectives. Hence, by applying this concept, MOO methods generate a set of optimal solutions on a Pareto frontier instead of a single solution. In other words, these algorithms allow the user to make a posteriori preference articulation [239] and enable the trade-off analysis after comprehending all non-dominated solutions. Table 6 shows that multi-objective genetic algorithms (MOGA), non-dominated sorting genetic algorithm-II (NSGA-II), and strength Pareto evolutionary algorithm (SPEA) are popular methods in multi-asset optimisation literature.

Some of the previous researchers directly applied GAs to generate Pareto optimal solutions, while some integrated GAs with their algorithms. Since it is difficult to determine solely from the literature how the GAs were utilised, studies that do not specify the methods in their studies are classified as MOGA in Table 6. The simplest application of GAs is vector evaluated genetic algorithm (VEGA), which was developed in the study of Schaffer [240]. In this algorithm, the simple GA was modified to accommodate vector-valued fitness measures, allowing sub-populations to be generated by performing selection in line with each objective in each generation. However, the author pointed out a major disadvantage of this method the speciation property. In a concave surface, this property makes the population split into different species, and each of which tends to move strongly towards a specific objective [241]. Hence, later algorithms applied the concept of inferiority to avoid this drawback.

NSGA-II was introduced by Deb et al. [242] and was named after the original NSGA as both methods utilised the concept of non-dominated sorting. In this concept, the algorithm assigns rank 0 to the most updated non-dominated subset of the population. Subsequently, a non-dominated subset is determined from the remaining population and is assigned rank 1. This process is repeated until the entire population is examined. The main difference between NSGA and NSGA-II is that the latter eliminates the drawback of the former in terms of computational complexity by incorporating the elitism. The use of elitism not only shows a significant improvement in run time, but also helps prevent the loss of effective solutions. 
Developed by Zitzler and Thiele [243], SPEA also uses Pareto dominance to assign fitness values to individuals as with NSGA-II. The main differences between SPEA and NSGA-II are that SPEA does not take into account whether members of the population dominate each other and that it is not reliant on any fitness sharing parameter. That is, the fitness of an individual is examined only by the archive of non-dominated solutions. Because of its successful applications, SPEA2 has been developed [244]. Significant improvements over the original SPEA are the improved fitness assignment scheme, the use of a nearest density estimation technique, and the new truncation method. These modifications guarantee the preservation of boundary solutions and lead to a more precise guidance of the search process. Noticeable advantages of SPEA2 are that it outperforms NSGA-II in higher-dimensional problems and that SPEA2 appears to produce less clustering and wider range of solutions. However, SPEA2 is proved to be inferior to NSGA-II in noisy environments [245].

MOO methods have been applied extensively to asset management problems at portfolio level. Table 6 shows that these methods are prominent in the studies pertaining to MR\&R project selection (DC v). As aforementioned, these methods enable users to understand the overall solutions on a Pareto frontier before finalising their decisions. Obviously, the concept of Pareto solutions is apposite to portfolio asset management problems mainly because these problems involve multiple performance measures that are not directly comparable. Moreover, these methods have also been proved to be advantageous to fleet management problems that require users to make a trade-off among incommensurable performance, cost, and risk measures. In spite of substantial benefits, MOO methods may not be appropriate for high-dimensional problems because the comprehension of multiple frontiers at a time is a daunting task for the decision maker and may lead to an unreasonable final solution. The next sub-section will investigate multi-criteria methods to address this situation.

\subsection{Multi-criteria decision analysis methods}

Multi-criteria decision analysis (MCDA) methods have been employed in asset management problems, especially at portfolio level, to integrate diverse values perceived by multiple stakeholders. Due to the high dimensionality of technical, economic, safety, and environmental criteria, it is too complicated for a decision maker to simultaneously make a direct trade-off among these measures. A possible strategy to deal with this problem is to assign weights to different components (objectives or assets), combine, and optimise multiple objectives concurrently. This paper further classifies MCDA methods into weighting and combining methods. Previous studies that applied MCDA weighting and combining methods are summarised in Table 7 and 8 respectively. 
Table 7

Summary of references on MCDA weighting methods

\begin{tabular}{|c|c|c|c|c|}
\hline Decision class & Reference & Asset category & Criteria & MCDA method(s) \\
\hline \multirow[t]{14}{*}{ iii } & [246] & SP: Production machines & Effect on production & AHP \\
\hline & & & Spare part type & \\
\hline & & & Replenishment time & \\
\hline & [247] & SP: Production machines & Inventory cost & AHP \\
\hline & & & Cost of production loss & \\
\hline & & & Safety index & \\
\hline & & & Environmental index & \\
\hline & [248] & SP: Production machines & Asset criticality index & $\mathrm{AHP}$ \\
\hline & & & Probability of failure & \\
\hline & & & Replenishment time & \\
\hline & & & Spare part availability & \\
\hline & [249] & SP: Power generators & Effect on production & AHP, Fuzzy MCDM \\
\hline & & & Spare part type & \\
\hline & & & Replenishment time & \\
\hline \multirow[t]{16}{*}{$\mathrm{v}$} & [100] & MP: Transportation assets & Condition index & AHP \\
\hline & & & Agency cost & \\
\hline & & & Operating cost & \\
\hline & & & Safety index & \\
\hline & & & Environmental index & \\
\hline & [165] & MP: Transportation assets & Condition index & AHP \\
\hline & & & Agency cost & \\
\hline & & & User cost & \\
\hline & & & Safety index & \\
\hline & & & Environmental index & \\
\hline & [250] & MP: Transportation assets & Condition index & AHP, SWING \\
\hline & & & Agency cost & \\
\hline & & & User cost & \\
\hline & & & Safety index & \\
\hline & [251] & MP: Infrastructure assets & Performance index & AHP \\
\hline & & & Maintenance cost & \\
\hline \multirow[t]{12}{*}{ vi } & [169] & SP: Pressure relief machines & Failure probability & Fuzzy MCDM \\
\hline & & & Operational impact & \\
\hline & & & Repair cost & \\
\hline & & & Safety index & \\
\hline & & & Environmental index & \\
\hline & [252] & SP: Production machines & Failure probability & AHP \\
\hline & & & Chance of non-detection & \\
\hline & & & Failure severity & \\
\hline & & & Maintenance cost & \\
\hline & [253] & SP: Production machines & Failure probability & AHP, Fuzzy MCDM \\
\hline & & & Chance of non-detection & \\
\hline & & & Failure severity & \\
\hline
\end{tabular}


Table 7 (continued)

\begin{tabular}{|c|c|c|c|c|}
\hline Decision class & Reference & Asset category & Criteria & MCDA method(s) \\
\hline \multirow[t]{12}{*}{ vi } & [254] & SP: Production machines & Failure probability & Fuzzy MCDM \\
\hline & & & Chance of non-detection & \\
\hline & & & Failure severity & \\
\hline & [255] & SP: Nuclear power plant & Failure probability & Fuzzy MCDM \\
\hline & & assets & Chance of non-detection & \\
\hline & & & Failure severity & \\
\hline & [256] & SP: Pavements & Condition index & Fuzzy MCDM \\
\hline & & & Failure severity & \\
\hline & [257] & SP: Pavements & Condition index & AHP \\
\hline & & & Maintenance cost & \\
\hline & & & Performance index & \\
\hline & & & Safety index & \\
\hline \multirow[t]{12}{*}{ vii } & [258] & SP: Roads & Performance index & AHP \\
\hline & & & User cost & \\
\hline & & & Safety index & \\
\hline & & & Environmental index & \\
\hline & [259] & SP: Pavements & Performance index & AHP \\
\hline & & & Maintenance cost & \\
\hline & & & Safety index & \\
\hline & & & Environmental index & \\
\hline & [184] & MP: Transportation assets & Asset value & SWING \\
\hline & & & Customer satisfaction & \\
\hline & & & Safety index & \\
\hline & & & Environmental index & \\
\hline
\end{tabular}

AHP = Analytic hierarchy process, SWING = swing weighting method, Fuzzy MCDM = Fuzzy multi-criteria decision-making method

Table 8

Summary of references on MCDA combining methods

\begin{tabular}{|c|c|c|c|c|}
\hline Decision class & Reference & Asset category & Criteria & MCDA method(s) \\
\hline \multirow[t]{2}{*}{$\mathrm{i}$} & [123] & F: Production machines & Makespan & WSM \\
\hline & & & Workload & \\
\hline \multirow[t]{10}{*}{$\mathrm{v}$} & [161] & SP: Bridges & Condition index & MAU \\
\hline & & & Safety index & \\
\hline & [198] & SP: Bridges & Condition index & GP \\
\hline & & & Maintenance cost & \\
\hline & [199] & SP: Pavements & Maintenance effect & WSM \\
\hline & & & Maintenance cost & \\
\hline & [260] & MP: Transportation assets & Condition index & GP \\
\hline & & & Maintenance cost & \\
\hline & [251] & MP: Infrastructure assets & Performance index & WSM \\
\hline & & & Maintenance cost & \\
\hline
\end{tabular}


Table 8 (continued)

\begin{tabular}{|c|c|c|c|c|}
\hline Decision class & Reference & Asset category & Criteria & MCDA method(s) \\
\hline \multirow[t]{6}{*}{ vi } & [261] & SP: Oil refinery assets & Failure frequency & WSM \\
\hline & & & Operational impact & \\
\hline & & & Operational condition & \\
\hline & & & Maintenance cost & \\
\hline & & & Safety & \\
\hline & & & Downtime length & \\
\hline \multirow[t]{13}{*}{ vii } & [262] & SP: Bridges & Performance index & $\varepsilon$-constraint method \\
\hline & & & Safety index & \\
\hline & & & User impact & \\
\hline & & & Operating cost & \\
\hline & [263] & SP: Roads & Condition index & $\varepsilon$-constraint method \\
\hline & & & Safety index & \\
\hline & & & Operating cost & \\
\hline & [180] & SP: Pavements & Performance index & WSM \\
\hline & & & Maintenance cost & \\
\hline & [183] & MP: Transportation assets & Performance index & MAU \\
\hline & & & Intervention cost & \\
\hline & [186] & MP: Transportation assets & Project benefit & $\varepsilon$-constraint method \\
\hline & [264] & MP: Transportation assets & Condition index & WSM \\
\hline
\end{tabular}

WSM = Weighted sum method, GP = Goal programming, MAU = Multi-attribute utility method.

\subsubsection{MCDA Weighting methods}

This sub-section discusses MCDA methods to determine appropriate weights assigned to different criteria. An assigned weight generally implies the relative importance of an objective or an asset to the decision maker. In most cases, these weights are deemed crucial as they directly influence the optimisation results. References that applied weighting methods are summarised in Table 7. It is apparent that analytic hierarchy process (AHP), which is an extension of a classic pair-wise comparison method, is the most used technique. Other weighting methods found in the previous literature is swing weighting method (SWING) and fuzzy multi-criteria decision-making method (Fuzzy MCDM).

AHP method was proposed by Saaty [265] as an extension of a classic pair-wise comparison model. In the pair-wise comparison method, a decision maker is requested to determine the importance of two criteria by specifying which and how much a criterion is more important than another. Relative importance scores are normalised to a total of 1 , which later become the weight inputs for an optimisation model. AHP develops upon this by constructing a matrix of pair-wise comparisons. The relative importance is subsequently scaled based on a set of prescribed rules and the final weights are calculated by applying arithmetic mean or least squares method. This process makes AHP superior to the classic pairwise as it ensures the consistency of the user's preferences. Apparently, main advantages of AHP are due to its simple calculation and its feasibility to a wide range of problems. However, since AHP is based on the subjective preference of a user, it may lead to inaccurate weights if there are a large number of alternatives that need to be compared. 
In SWING, a decision maker is asked to rank criteria based on their changes in value. That is, the decision maker has to select the most important criterion by examining the value of improvement from the worst to the best scenario. The most important criterion is subsequently assigned a highest score. This process is then repeated with a lower score assigned to each repetition until all the criteria are considered. The importance weights are finally derived from the normalised scores. A major advantage of SWING is that it does not require the value function of objectives. Only attribute ranges (worst and best scenario values) must be known. Moreover, SWING is also of very intermediate complexity and therefore easy to apply. However, like classic pair-wise method, SWING is based on direct rating and does not include the consistency check. Another disadvantage occurs when attribute ranges are extreme, for instance, unusually low worst values. This may lead to illogical outcomes if the decision maker prefers to avoid these extreme values.

The fuzzy set theory was introduced to the decision theory by Bellman and Zadeh [266] with an attempt to deal with the vagueness of decision makers. In the classical set theory, the assessment of a set membership follows a bivalent condition; that is, an element is either a member or non-member of a set. In contrast, the fuzzy set theory allows an element to be a partial member of a set and indicates the membership by a value between 0 and 1 . The fuzzy set theory offers an ideal solution for evaluating human preference. In reality, due to the inconsistency and uncertainty of human perception, it is a daunting task to assign accurate weights to convey the preference of the decision maker, who usually expresses the preference in linguistic terms. Thus, previous researchers have applied the fuzzy set theory to capture this uncertainty. Fuzzy MCDM is proved to be an effective tool to bolster the prioritisation procedure as the weights can be derived without entailing any comparison methods. Furthermore, the fuzzy set theory has also been integrated with other MCDA methods such as Fuzzy AHP [249] and Fuzzy TOPSIS [254].

Table 7 shows that the aforementioned weighting methods have been applied to various DCs including iii, v, vi, and vii. In spare-part management problems (DC iii), weighting methods are used to support the classification of spare parts and become an effective tool for multi-criteria inventory management when combined with other existing classification methods. Likewise, in asset prioritisation problems (DC vi) these methods are used to bolster the criticality analysis as they are employed to develop various multi-attribute failure mode analysis tools. Weighting methods are directly applied in MR\&R project selection and budget allocation problems (DC v and vii) as they are used to deal with conflicting criteria of a portfolio asset management. Although weighting methods are discernible and applicable to a wide range of problems, an obvious disadvantage is that they require subjective judgement of the decision maker. Thus, it is highly possible that a single perspective may not yield the maximum benefit for the whole multi-asset system that involves multiple stakeholders.

\subsubsection{MCDA Combining methods}

After the importance of each objective or asset is assigned, the weights are accumulated to derive the final solution. Methods that enable the accumulation of these weights are referred to as MCDA combining methods in this paper and are summarised in Table 8. 
Method adopted by previous researchers to address multi-asset problems include weighted sum method (WSM), goal programming (GP), $\varepsilon$-constraint method, and multi-attribute utility (MAU) method.

WSM is the most straightforward approach to combine multiple objectives. In this approach, positive weights obtained from a weighting method are multiplied with their corresponding objectives [238]. All the products are subsequently combined by addition and constitute a single objective. Because of simplicity and applicability, this method is one of the most used combining methods in previous studies. However, due to the priori selection of weights, this method does not guarantee that the concomitant solution is reasonable because it can result in an extreme set of solutions. Another disadvantage is that a subtle change in weight can lead to a drastic change in the optimal solution. Previous researchers also employed WSM in a posteriori sense by varying weights to generate a Pareto frontier (e.g. [251]). Nonetheless, resultant solutions do not always ensure a widespread or even distribution, making posteriori WSMs generally inferior to MOO methods.

GP is an extension of LP to address multi-objective problems [267]. In this optimisation programme, each of the objectives is assigned a goal value to be achieved. The problem is subsequently formulated in a way that undesirable deviations from these goals are minimised and the integration of these deviations is achieved by a weighted summation. Obviously, GP is deemed very effective for problems that have clear target objectives. Other advantages of GP are that it is simple to implement and that it can handle a large number of variables; these are enabled by LP algorithms. Nevertheless, GP also has a significant weakness as the derived solution may not lie on the Pareto frontier and hence is not the best possible result.

In $\varepsilon$-constraint method, only one of the objective functions is selected as a main function to be optimised while other unselected objective functions are converted into constraints with specified bounds [268]. Hence, a multi-criteria problem becomes a single-objective optimisation problem. A major advantage of $\varepsilon$-constraint method over weight-based methods is that $\varepsilon$-constraint method is also effective for a multi-objective optimisation problem that involves integer variables. However, an inappropriate selection of the main objective or constraints could lead to an infeasible solution. As for the posteriori use, $\varepsilon$-constraint method has also been proved to be superior to weighted-sum because it can create a better widespread distribution of Pareto solutions [269]. The $\varepsilon$-constraint method is also used as a supplement to other MCDA methods such as surrogate worth trade-off method (e.g. [186] and [187]), which enables the incorporation of decision-maker assessment in a trade-off analysis.

MAU method is an extension of conventional utility theory. The first step of MAU method is to develop a single-attribute utility (SAU) function, which is a numerical function that represents the decision maker's attitude towards risk within each attribute and ranges from 0 to 1 [270]. After all SAU functions are constructed, they are combined into an MAU function that reflects the decision maker's attitude towards risk in the overall problem space. A key advantage of the MAU method is that it can be easily combined with other optimisation methods as utility functions are normalised. This method generally produces a reasonable output if the linear standardisation method can be used to transform raw scores into utility 
functions. However, this method may require a high computational cost and may not produce an accurate output if original attribute scores require complex conversion operations [238].

Table 8 shows that the MCDA combining methods are extensively employed in portfolio asset management problems in MR\&R project selection and budget allocation (DC $\mathrm{v}$ and vii). Apparently, it is an onerous task for a decision maker to simultaneously discern solutions from multi-dimensional perspectives and arrive at a sound decision. Therefore, combining method that prunes solutions from a large Pareto set and offers a single solution is considered an effective decision support framework. However, since these combining methods are based on either the subjective weighting methods or unwarranted assumptions on conversion functions, the user cannot be certain that the derived solution is definitive.

\section{Discussion}

In this section, we summarise the findings from the literature to provide guidance to the research community. Firstly, we discuss main differences between multi-asset and multicomponent systems and elucidate why multi-component models may not be compatible with multi-asset problems:

i. Indistinct asset configuration: Since multi-asset systems do not require that assets work collectively in one specific location, configurations among assets are generally indistinct. That is, different assets in a fleet or a portfolio may contribute unequally to the overall system value. This characteristic of a portfolio is fundamentally opposed to that of a multi-component system in which the relationship among components (e.g. series and parallel) is clearly defined. Therefore, despite a plenty of studies on a system of homogeneous heterogeneous components, reliability models for multi-component systems are still incompatible with portfolio systems.

ii. Impacts on multiple stakeholders: Due to a number of different assets in a multi-asset system, it is likely that this system is large in scale when compared to multi-component systems. This aspect brings about effects that the system has not only on internal stakeholders (e.g. asset managers), but also on external stakeholders (e.g. users). It is apparent that the former generally aims at delivering a cost-effective service, while the latter tends to prioritise system performance and reliability over cost. This aspect is also opposed to that of a multi-component system which typically entails single stakeholder.

Moreover, to justify our further classification of multi-asset systems, we also highlight the characteristics that distinguish portfolios from fleets:

i. Diverse intervention effects and options: In a single-category portfolio, although similar intervention options (e.g. inspection and repair activities) may be applied to any asset in the system, they can have different effects on various assets. Assets in the system could vary in life cycles, intervention costs, risk thresholds, and condition improvement levels. The system becomes even more diverse in a multi-category portfolio as different 
inspection and repair activities are required for different types of assets. Hence, fleet optimisation models in which similar intervention effects and options can be applied to all asset members may not be pertinent to a portfolio problem.

ii. Incommensurable performance metrics: The problem of multi-category portfolio management is deemed complicated not only because of conflicts between internal and external stakeholders, but also because of those within the organisation itself. Despite sharing common resources such as workforce and budget, different asset categories are generally managed by different entities. Additionally, since different performance metrics are required for different assets, objectives of these departments can be completely different. This diversity poses an intractable problem on resource allocation, because the conversion of different performance, cost, and risk metrics into organisational values requires subjective judgment of the management.

Having delved into different types of asset dependencies, we found that the following problems have not been tackled in fleets and portfolios:

i. Fleet load-sharing dependencies: This relates to fleets of assets operating in a $k$-out-of$N$ system, where the deterioration or failure of one asset requires the other assets to share the burden by increasing their workload. The incorporation of this dependency could bring about a more pragmatic solution.

ii. Portfolio asset substitution effects: For a portfolio in which assets operate in a neighbouring area, the failure of an asset can accelerate the degradation process of other assets in the same network through a substitution effect. That is, if an asset in a portfolio fails, other assets with similar performance features have to cope with additional demand.

iii. Portfolio workforce restrictions: This dependence arises from either limited internal workforce or restricted availability of contractors. The inadequacy of maintenance specialists and tools may curtail the company's ability to undertake simultaneous intervention activities for different assets in a portfolio.

Lastly, as explored in the previous section, we also identified weaknesses in the current modelling approaches that deal with fleet and portfolio decisions. To overcome these shortcomings, we suggest that future studies pursue the following avenues:

i. Inclusion of holistic objectives and dependencies in fleet management: Fleet management optimisation problems currently found in the literature often consider a limited set of objectives (e.g. cost and reliability) in the model formulation. This limits practical adoption since fleet management decisions in reality involve other important objectives such as emissions, performance, and safety. Moreover, in such DC as asset and equipment selection on which the studies are not fully established, assets in a system are readily assumed independent. Thus, the incorporation of performance relationship and specialised tool and workforce limitation into the formulation would greatly improve applicability of future models. 
ii. Exploitation of interconnected data: The majority of current multi-asset studies are reliant on an assumption that the condition of an asset obediently follows a predefined function. The application of interrelated computing technologies allows users to utilise real-time data to update this information, leading to a more accurate prediction of asset conditions. Although the use of interconnected data has been considered in various multi-component maintenance papers, not many studies with an emphasis on fleets and portfolios have taken cognisance of this aspect. An effective implementation of these technologies would result in a more pragmatic predictive maintenance strategy that could substantially reduce unnecessary cost and enhance system performance.

iii. Data-driven value-based decision-making: Although later researchers have endeavoured to incorporate multiple objectives into portfolio asset management problems, the final decision to make a trade-off among these objectives is based on a user's preference. This does not ensure that the resultant strategy would offer the maximum advantage for an organisation. A data-driven approach that can comprehensively capture values perceived by system stakeholders would allow an organisation to realise the genuine importance of each objective, constituting a significant improvement in decision-making on MR\&R project selection and budget allocation.

\section{Conclusions}

This paper reviewed the literature on multi-unit asset management systems with an emphasis on fleets and portfolios. We began with collating previous studies on systems with multiple units to investigate how the term 'multi-unit system' and its related expressions are adopted in different contexts. In accordance with essential features such as the diversity of system members and intervention options, multi-unit systems are primarily categorised into multi-component and multi-asset systems. We further classified the latter into a fleet - a system of homogeneous assets - and a portfolio - a system of heterogeneous assets. We demonstrated that models that are considered effective in a multi-component system may not be applicable to a multi-asset system due to some dissimilar characteristics of these categories.

To highlight dissimilarities among categories, we drew three types of previous multicomponent dependencies - performance, stochastic, and resource dependence - and revised these notions in order that they are applicable to multi-asset systems. We successfully identified potential niches in both fleet and portfolio research. Our findings revealed that performance and stochastic interactions are more apparent in multi-component systems than in multi-asset systems and showed the opposite for resource dependencies.

Furthermore, we scrutinised research contributions made by previous researchers who focused on multi-asset systems. Typical problems pertaining to these systems were categorised into seven decision classes. We also gathered state-of-the-art references that 
belong to each decision class and discussed how problems in each asset category were dealt with in previous research. We found that the majority of multi-asset problems stem from shared facility (intervention scheduling), resource (spare parts management), and budget (MR\&R project selection, asset prioritisation, and budget allocation).

More importantly, we also investigated various solution methods applied in fleet and portfolio studies. It is apparent that decision-making at multi-asset level affects a wider range of stakeholders and involves more criteria when compared to that at multi-component level. Factors considered in multi-asset problems include both direct technical measures (e.g. reliability, safety, and cost) and indirect functional measures (e.g. production output and other user-based performance metrics). Hence, methods for the enhancement of safety and reliability of multi-asset systems are not only complex models that focus on a single objective, but also frameworks that incorporate multiple criteria from different dimensions. Thus, besides single-objective optimisation methods, various $\mathrm{MOO}$ and MCDA methods applied in previous studies were also investigated. To facilitate the selection of conductive techniques to readers' interests, we also explicated the mechanisms behind these techniques along with their advantages and drawbacks.

Lastly, we also provided our insights into current trends in asset management research and offered potential research avenues. The findings of our review on asset dependencies pointed out possible types of dependencies that could exist in reality, but have not been examined in existing studies. In addition, we also identified the shortcomings of current modelling approaches. These findings enable us to put forward suggestions on the inclusion of different value components and the deployment of data-driven approach to mitigate the subjectivity in decision-making in fleet and portfolio asset management.

\section{Acknowledgments}

We would like to thank three anonymous reviewers for their constructive comments that help improve this paper. Also, we wish to acknowledge the financial support provided by Mahidol University to the first author. 


\section{References}

[1] Dekker R, Wildeman RE, Van Der Duyn Schouten FA. A review of multi-component maintenance models with economic dependence. Math Methods Oper Res 1997;45:41135.

[2] Nicolai RP, Dekker R. Optimal Maintenance of Multi-component Systems: A Review. vol. 8. 2008. doi:10.1007/978-1-84800-011-7_11.

[3] Olde Keizer MCA, Flapper SDP, Teunter RH. Condition-based maintenance policies for systems with multiple dependent components: A review. Eur J Oper Res 2017;261:405-20. doi:10.1016/j.ejor.2017.02.044.

[4] Wang R, Chen N. A survey of condition-based maintenance modeling of multicomponent systems. vol. 2016- December, 2016, p. 1664-8. doi:10.1109/IEEM.2016.7798160.

[5] Cho DI, Parlar M. A survey of maintenance models for multi-unit systems. Eur J Oper Res 1991;51:1-23. doi:10.1016/0377-2217(91)90141-H.

[6] Wang H. A survey of maintenance policies of deteriorating systems. Eur J Oper Res 2002;139:469-89. doi:10.1016/S0377-2217(01)00197-7.

[7] Alaswad S, Xiang Y. A review on condition-based maintenance optimization models for stochastically deteriorating system. Reliab Eng Syst Saf 2017;157:54-63. doi:10.1016/j.ress.2016.08.009.

[8] ISO (International Organization for Standardization). ISO 55000:2014 Asset management - Overview, principles and terminology 2014.

[9] Amadi-Echendu JE, Willett R, Brown K, Hope T, Lee J, Mathew J, et al. What is engineering asset management? vol. 1. 2010. doi:10.1007/978-1-84996-178-3_1.

[10]The Institute of Asset Management. Asset Management - an anatomy. 3rd ed. Bristol, United Kingdom: 2015.

[11]Osaki S, Asakura T. A Two-Unit Standby Redundant System with Repair and Preventive Maintenance. J Appl Probab 1970;7:641-8. doi:10.2307/3211943.

[12]Branson MH, Shah B. Reliability Analysis of Systems Comprised of Units with Arbitrary Repair-Time Distributions. Reliab IEEE Trans On 1971;R-20:217-23. doi:10.1109/TR.1971.5216139.

[13]Subramanian R, Venkatakrishnan KS. Reliability of a 2-Unit Standby Redundant System with Repair, Maintenance and Standby Failure. Reliab IEEE Trans On 1975;R-24:139-42. doi:10.1109/TR.1975.5215118.

[14]Kumar A. Steady-State Profit in a 2-unit Standby System. Reliab IEEE Trans On 1976;R25:105-8. doi:10.1109/TR.1976.5214993.

[15]Fard N, Zheng X. An approximate method for non-repairable systems based on oppurtunistic replacement policy. Reliab Eng Syst Saf 1991;33:277-88. doi:10.1016/09518320(91)90064-E.

[16]Park JH, Lee SC, Hong JW, Lie CH. An optimal block preventive maintenance policy for a multi-unit system considering imperfect maintenance. Asia-Pac J Oper Res 2009;26:83147. doi:10.1142/S021759590900250X.

[17]Noriega HC, Frutuoso e Melo PF. Non-stationary point-process maintenance-model for multi-unit systems, 1998, p. 189-94.

[18]Khan NM, Gupta A. New Models for Maintenance of Series and Parallel Systems. IEEE Trans Reliab 1986;35:68-70. doi:10.1109/TR.1986.4335350. 
[19]Jansen J, Van Der Duyn Schouten F. Maintenance optimization on parallel production units. IMA J Manag Math 1995;6:113-34. doi:10.1093/imaman/6.1.113.

[20]Gürler U, Kaya A. A maintenance policy for a system with multi-state components: An approximate solution. Reliab Eng Syst Saf 2002;76:117-27. doi:10.1016/S09518320(01)00125-9.

[21]Trippi RR, Khumawala BM. SOLUTION OF THE MULTI-ASSET FINITE HORIZON INVESTMENT RENEWAL PROBLEM. Manag Sci 1975;21:1156-63.

[22]Stinson JP, Khumawala BM. The replacement of machines in a serially dependent multimachine production system. Int J Prod Res 1987;25:677-88. doi:10.1080/00207548708919870.

[23]Semple J, Sarkis J. An optimal multi-machine replacement policy in a serially dependent production system. Int J Prod Res 1994;32:2657-67. doi:10.1080/00207549408957090.

[24]Reimann J, Kacprzynski G, Cabral D, Marini R. Using condition based maintenance to improve the profitability of performance based logistic contracts, 2009.

[25] Yeo H, Yoon Y, Madanat S. Maintenance optimization for heterogeneous infrastructure systems: Evolutionary algorithms for bottom-up methods. Sustain. Resilient Crit. Infrastruct. Syst. Simul. Model. Intell. Eng., 2010, p. 185-99. doi:10.1007/978-3-642-11405$2 \_7$.

[26]Rama D, Andrews JD. A holistic approach to railway infrastructure asset management. Int J Perform Eng 2015;11:107-20.

[27]Alj A, Haurie A. HIERARCHICAL CONTROL OF A POPULATION PROCESS WITH APPLICATION TO GROUP PREVENTIVE MAINTENANCE., 1981, p. 333-8.

[28]Knessl C. On the distribution of the maximum number of broken machines for the repairman problem. SIAM J Appl Math 1994;54:508-47.

[29]Dietz DC, Rosenshine M. Optimal specialization of a maintenance workforce. IIE Trans Inst Ind Eng 1997;29:423-33. doi:10.1080/07408179708966348.

[30]Kenne JP, Boukas EK. Production and corrective maintenance planning problem of a failure prone manufacturing system. vol. 2, 1997, p. 1013-4.

[31] Suryanarayan S. ROLE OF VIBRATION MEASUREMENT AND ANALYSIS IN MAINTENANCE ENGINEERING. J Inst Eng India Part ND New Div 1980;62 ND 2:8996.

[32]Zheng X, Fard N. A Maintenance Policy for Repairable Systems Based on Opportunistic Failure-Rate Tolerance. IEEE Trans Reliab 1991;40:237-44. doi:10.1109/24.87134.

[33]Mancuso A, Compare M, Salo A, Zio E, Laakso T. Risk-based optimization of pipe inspections in large underground networks with imprecise information. Reliab Eng Syst Saf 2016;152:228-38. doi:10.1016/j.ress.2016.03.011.

[34]Jain S, Roelofs F, Oosterlee CW. Decision-support tool for assessing future nuclear reactor generation portfolios. Energy Econ 2014;44:99-112. doi:10.1016/j.eneco.2014.03.021.

[35] Cowie R, Whytehead R. Lundenwic: The archaeological evidence for middle Saxon London. Antiquity 1989;63:706-18. doi:10.1017/S0003598X00076845.

[36]Scher RM, Benford H. SOME ASPECTS OF FUEL ECONOMY IN BULK CARRIER DESIGN AND OPERATION. Univ Mich Dep Nav Archit Mar Eng Rep 1980.

[37]Triner DA, Phillips MJ. RELIABILITY OF EQUIPMENT FITTED TO A FLEET OF SHIPS., 1986.

[38]Perakis AN, Papadakis N. Fleet deployment optimization models. Part 1. Marit Policy Manag 1987;14:127-44. doi:10.1080/03088838700000015. 
[39] Yang J-N, Trapp WJ. Reliability analysis of aircraft structures under random loading and periodic inspection. AIAA J 1974;12:1623-30. doi:10.2514/3.49570.

[40]Kabir ABMZ. Evaluation of overhaul/replacement policy for a fleet of buses. J Qual Maint Eng 1996;2:49-59. doi:10.1108/13552519610130440.

[41]Chamberlin M, Weerasinghe M. Maintenance depot transformation, not just a face-lift. Proc Inst Mech Eng Part F J Rail Rapid Transit 1998;212:177-87.

[42]Christer AH, Waller WM. An operational research approach to planned maintenance: modelling p.M. for a vehicle fleet. J Oper Res Soc 1984;35:967-84. doi:10.1057/jors.1984.193.

[43]Wouters PAAF, Van Schijndel A, Wetzer JM. Remaining lifetime modeling of power transformers: Individual assets and fleets. IEEE Electr Insul Mag 2011;27:45-51. doi:10.1109/MEI.2011.5871368.

[44]Zhang L, Cao Q, Lee J. Performance assessment for a fleet of machines using a combined method of ant-based clustering and CMAC. Adv Mech Eng 2013;2013. doi:10.1155/2013/603071.

[45]Liang WK, Balcioglu B, Svaluto R. Scheduling policies for a repair shop problem. Ann Oper Res 2013;211:273-88. doi:10.1007/s10479-013-1412-6.

[46]Sarma VVS, Rao AK. Queuing Models for Estimating Aircraft Fleet Availability. IEEE Trans Reliab 1977;R-26:253-6. doi:10.1109/TR.1977.5220144.

[47]Park KS. (S - 1,S) Spare-Part Inventory Policy for Fleet Maintenance. IEEE Trans Reliab 1981;R-30:481-3. doi:10.1109/TR.1981.5221182.

[48]Van Horenbeek A, Scarf PA, Cavalcante CAV, Pintelon L. The effect of maintenance quality on spare parts inventory for a fleet of assets. IEEE Trans Reliab 2013;62:596-607. doi:10.1109/TR.2013.2270409.

[49]Lee J, Kao H-A, Yang S. Service innovation and smart analytics for Industry 4.0 and big data environment. vol. 16, 2014, p. 3-8. doi:10.1016/j.procir.2014.02.001.

[50]Feng Q, Bi W, Chen Y, Ren Y, Yang D. Cooperative game approach based on agent learning for fleet maintenance oriented to mission reliability. Comput Ind Eng 2017;112:221-30. doi:10.1016/j.cie.2017.08.028.

[51]Sriram C, Haghani A. An optimization model for aircraft maintenance scheduling and reassignment. Transp Res Part Policy Pract 2003;37:29-48. doi:10.1016/S0965-8564(02)000046.

[52]Haghani A, Shafahi Y. Bus maintenance systems and maintenance scheduling: Model formulations and solutions. Transp Res Part Policy Pract 2002;36:453-82. doi:10.1016/S0965-8564(01)00014-3.

[53]Monnin M, Voisin A, Leger J-B, Iung B. Fleet-wide health management architecture, 2014, p. $547-54$.

[54]Rawat M, Lad BK. An integrated approach for fleet level maintenance planning. Int J Perform Eng 2015;11:229-42.

[55]Godoy DR, Pascual R, Knights P. A decision-making framework to integrate maintenance contract conditions with critical spares management. Reliab Eng Syst Saf 2014;131:102-8. doi:10.1016/j.ress.2014.06.022.

[56]Ritchken P, Wilson JG. (m, T) Group Maintenance Policies. Manag Sci 1990;36:632-9.

[57]Sheu S-H, Jhang J-P. A generalized group maintenance policy. Eur J Oper Res 1997;96:23247. doi:10.1016/S0377-2217(96)00073-2.

[58]Salari N, Makis V. Comparison of two maintenance policies for a multi-unit system considering production and demand rates. Int J Prod Econ 2017;193:381-91. doi:10.1016/j.ijpe.2017.08.003. 
[59] Ko YM, Byon E. Condition-based joint maintenance optimization for a large-scale system with homogeneous units. IISE Trans 2017;49:493-504. doi:10.1080/0740817X.2016.1241457.

[60]Wang R, Chen G, Zhang W. Optimization modeling of system lifecycle cost with availability constraints and inventory optimization, 2017. doi:10.1109/PHM.2016.7819916.

[61]Zhang X, Zeng J. Joint optimization of condition-based opportunistic maintenance and spare parts provisioning policy in multiunit systems. Eur J Oper Res 2017;262:479-98. doi:10.1016/j.ejor.2017.03.019.

[62] Gertsbakh IB. Optimal Group Preventive Maintenance of a System with Observable State Parameter. Adv Appl Probab 1984;16:923-5. doi:10.2307/1427348.

[63]Bunday BD. The maintenance and availability of unidirectionally patrolled stations. IMA J Manag Math 1995;6:25-38. doi:10.1093/imaman/6.1.25.

[64]Wilson JG. A Note on Variance Reducing Group Maintenance Policies. Manag Sci 1996;42:452-6.

[65]Jain M. An (m, M) machine repair problem with spares and state dependent rates: A diffusion process approach. Microelectron Reliab 1997;37:929-33.

[66]Markowitz H. PORTFOLIO SELECTION. J Finance 1952;7:77-91. doi:10.1111/j.15406261.1952.tb01525.x.

[67]Mills GRW, Deka L, Price ADF, Rich-Mahadkar S, Pantzartzis E, Sellars P. Critical infrastructure risk in NHS England: predicting the impact of building portfolio age. Int J Strateg Prop Manag 2015;19:159-72. doi:10.3846/1648715X.2015.1029562.

[68]Christen M, Adey BT, Wallbaum H. On the usefulness of a cost-performance indicator curve at the strategic level for consideration of energy efficiency measures for building portfolios. Energy Build 2016;119:267-82. doi:10.1016/j.enbuild.2016.02.056.

[69] Abu-Tair A, Al Hussain A. Use of Just in Time Maintenance of Reinforced Concrete Bridge Structures based on Real Historical Data Deterioration Models. vol. 83, 2016. doi:10.1051/matecconf/20168306002.

[70]McKoy R. London underground - Successful outcome of bridge assessment programme. Proc Inst Civ Eng Bridge Eng 2016;169:113-25. doi:10.1680/jbren.15.00013.

[71]Srinivasan R, Parlikad AK. Value based maintenance prioritization for a portfolio of bridges, 2016, p. 715-20. doi:10.1680/tfitsi.61279.715.

[72]Moser D, Del Buono M, Jahn U, Herz M, Richter M, De Brabandere K. Identification of technical risks in the photovoltaic value chain and quantification of the economic impact. Prog Photovolt Res Appl 2017;25:592-604. doi:10.1002/pip.2857.

[73]Morales-Torres A, Serrano-Lombillo A, Escuder-Bueno I, Altarejos-GarcÃ-a L. The suitability of risk reduction indicators to inform dam safety management. Struct Infrastruct Eng 2016;12:1465-76. doi:10.1080/15732479.2015.1136830.

[74]Yianni PC, Rama D, Neves LC, Andrews JD, Castlo D. A Petri-Net-based modelling approach to railway bridge asset management. Struct Infrastruct Eng 2017;13:287-97. doi:10.1080/15732479.2016.1157826.

[75]Zhang W, Wang W. Whole life cost modelling in infrastructure asset management, 2013, p. 1695-7. doi:10.1109/QR2MSE.2013.6625902.

[76]Madaus M. The air force infrastructure portfolio. Mil Eng 2009;101:63-4.

[77]Green W, Bacon S, Dockrill B. Engineered maintenance design of newcastle port assets, 2013, p. 328-33.

[78]Wang K-S, Tsai Y-T, Lin C-H. A study of replacement policy for components in a mechanical system. Reliab Eng Syst Saf 1997;58:191-9. 
[79]Alrabghi A, Tiwari A. A novel approach for modelling complex maintenance systems using discrete event simulation. Reliab Eng Syst Saf 2016;154:160-70. doi:10.1016/j.ress.2016.06.003.

[80]Pargar F, Kauppila O, Kujala J. Integrated scheduling of preventive maintenance and renewal projects for multi-unit systems with grouping and balancing. Comput Ind Eng 2017;110:43-58. doi:10.1016/j.cie.2017.05.024.

[81]Sacco T, Sansavini G, Compare M, Zio E. Robust portfolio modelling methodological approach to gb gas grid risk analysis via a simplified network version, 2017, p. 281.

[82]Maaroufi G, Chelbi A, Rezg N, Daoud A-K. A nearly optimal inspection policy for a twocomponent series system. J Qual Maint Eng 2015;21:171-85. doi:10.1108/JQME-11-20130074.

[83]Do P, Scarf P, Lung B. Condition-based maintenance for a two-component system with dependencies. IFAC-Pap 2015;28:946-51. doi:10.1016/j.ifacol.2015.09.648.

[84] Li H, Deloux E, Dieulle L. A condition-based maintenance policy for multi-component systems with Lévy copulas dependence. Reliab Eng Syst Saf 2016;149:44-55. doi:10.1016/j.ress.2015.12.011.

[85]Olde Keizer MCA, Teunter RH, Veldman J, Babai MZ. Condition-based maintenance for systems with economic dependence and load sharing. Int J Prod Econ 2018;195:319-27. doi:10.1016/j.ijpe.2017.10.030.

[86]De Smidt-Destombes KS, Van der Heijden MC, Van Harten A. On the availability of a kout-of-N system given limited spares and repair capacity under a condition based maintenance strategy. Reliab Eng Syst Saf 2004;83:287-300. doi:10.1016/j.ress.2003.10.004.

[87] Li W, Zuo MJ. Reliability evaluation of multi-state weighted k-out-of-n systems. Reliab Eng Syst Saf 2008;93:161-8. doi:10.1016/j.ress.2006.11.009.

[88] Liu B, Xu Z, Xie M, Kuo W. A value-based preventive maintenance policy for multicomponent system with continuously degrading components. Reliab Eng Syst Saf 2014;132:83-9. doi:10.1016/j.ress.2014.06.012.

[89]Mercier S, Pham HH. A condition-based imperfect replacement policy for a periodically inspected system with two dependent wear indicators. Appl Stoch Models Bus Ind 2014;30:766-82. doi:10.1002/asmb.2011.

[90]Nahas N, Nourelfath M. Ant system for reliability optimization of a series system with multiple-choice and budget constraints. Reliab Eng Syst Saf 2005;87:1-12. doi:10.1016/j.ress.2004.02.007.

[91]Mohamed A-A, Leemis LM, Ravindran A. Optimization techniques for system reliability: a review. Reliab Eng Syst Saf 1992;35:137-46. doi:10.1016/0951-8320(92)90033-H.

[92]Lai M-T, Yuan J. Cost-Optimal replacement policy $(\mathrm{N} *, \mathrm{n} *)$ for a parallel system with common cause failure. Reliab Eng Syst Saf 1991;32:339-47. doi:10.1016/09518320(91)90007-T.

[93]Moustafa MS. Reliability analysis of K-out-of-N: G systems with dependent failures and imperfect coverage. Reliab Eng Syst Saf 1997;58:15-7. doi:10.1016/S0951-8320(97)00050-1.

[94]Zuo MJ, Liang M. Reliability of multistate consecutively-connected systems. Reliab Eng Syst Saf 1994;44:173-6. doi:10.1016/0951-8320(94)90009-4.

[95]Rasmekomen N, Parlikad AK. Maintenance optimization for asset systems with dependent performance degradation. IEEE Trans Reliab 2013;62:362-7. doi:10.1109/TR.2013.2257056. 
[96]El Moudani W, Mora-Camino F. A dynamic approach for aircraft assignment and maintenance scheduling by airlines. J Air Transp Manag 2000;6:233-7. doi:10.1016/S09696997(00)00011-9.

[97]Safaei N, Banjevic D, Jardine AKS. Workforce-constrained maintenance scheduling for military aircraft fleet: A case study. Ann Oper Res 2011;186:295-316. doi:10.1007/s10479011-0885-4.

[98]Mattila V, Virtanen K. Maintenance scheduling of a fleet of fighter aircraft through multiobjective simulation-optimization. SIMULATION 2014;90:1023-40. doi:10.1177/0037549714540008.

[99]Gokey J, Klein N, Mackey C, Santos J, Pillutla A, Tucker S. Development of a prioritization methodology for maintaining Virginia's bridge infrastructure systems, 2009, p. 252-7. doi:10.1109/SIEDS.2009.5166190.

[100] Li Z, Sinha KC. Methodology for the determination of relative weights of highway asset management system goals and of performance measures. J Infrastruct Syst 2009;15:95-105. doi:10.1061/(ASCE)1076-0342(2009)15:2(95).

[101] Thomas LC. A survey of maintenance and replacement models for maintainability and reliability of multi-item systems. Reliab Eng 1986;16:297-309. doi:10.1016/01438174(86)90099-5.

[102] Vacheyroux G, Corotis R. Strategies of investment in the management of urban bridges: a life-cycle approach illustrated for Paris. Struct Infrastruct Eng 2013;9:1080-93. doi:10.1080/15732479.2012.665464.

[103] Tan L, Yang J, Cheng Z, Guo B. Optimal replacement policy for cold standby system. Chin J Mech Eng Engl Ed 2011;24:316-22. doi:10.3901/CJME.2011.02.316.

[104] Camci F. System maintenance scheduling with prognostics information using genetic algorithm. IEEE Trans Reliab 2009;58:539-52. doi:10.1109/TR.2009.2026818.

[105] Wang L, Chu J, Mao W. An optimum condition-based replacement and spare provisioning policy based on Markov chains. J Qual Maint Eng 2008;14:387-401. doi:10.1108/13552510810909984.

[106] Sheng J, Prescott D. A hierarchical coloured Petri net model of fleet maintenance with cannibalisation. Reliab Eng Syst Saf 2017;168:290-305. doi:10.1016/j.ress.2017.05.043.

[107] Bai Q, Labi S, Sinha KC. Trade-Off Analysis for Multiobjective Optimization in Transportation Asset Management by Generating Pareto Frontiers Using Extreme Points Nondominated Sorting Genetic Algorithm II. J Transp Eng 2012;138:798-808. doi:10.1061/(ASCE)TE.1943-5436.0000369.

[108] Anastasopoulos PC, Florax RJGM, Labi S, Karlaftis MG. Contracting in highway maintenance and rehabilitation: Are spatial effects important? Transp Res Part Policy Pract 2010;44:136-46. doi:10.1016/j.tra.2009.12.002.

[109] Anastasopoulos PC, McCullouch BG, Gkritza K, Mannering FL, Sinha KC. Cost savings analysis of performance-based contracts for highway maintenance operations. J Infrastruct Syst 2010;16:251-63. doi:10.1061/(ASCE)IS.1943-555X.0000012.

[110] Shrestha PP, Shrestha K. An evaluation of current practices of road maintenance contracting methods, 2014, p. 1408-17. doi:10.1061/9780784413517.0144.

[111] Shrestha PP, Shrestha K, Said A, Lidder M. Factors affecting the selection of in-house and outsourcing road maintenance methods and assessment of their benefits. J Infrastruct Syst 2017;23. doi:10.1061/(ASCE)IS.1943-555X.0000315.

[112] Karabakal N, Bean JC, Lohmann JR. Solving large replacement problems with budget constraints. Eng Econ 2000;45:290-308. doi:10.1080/00137910008967554. 
[113] Childress S, Durango-Cohen P. On parallel machine replacement problems with general replacement cost functions and stochastic deterioration. Nav Res Logist 2005;52:409-19. doi:10.1002/nav.20088.

[114] Ohlmann JW, Bean JC. Resource-constrained management of heterogeneous assets with stochastic deterioration. Eur J Oper Res 2009;199:198-208. doi:10.1016/j.ejor.2008.11.005.

[115] Cao W, Jia X, Hu Q, Zhao J, Wu Y. A literature review on selective maintenance for multi-unit systems 2018. doi:10.1002/qre.2293.

[116] Hartman JC, Tan CH. Equipment replacement analysis: A literature review and directions for future research. Eng Econ 2014;59:136-53. doi:10.1080/0013791X.2013.862891.

[117] Lee C-Y. Machine scheduling with an availability constraint. J Glob Optim 1996;9:395416. doi:10.1007/BF00121681.

[118] Kaspi M, Montreuil B. On the scheduling of identical parallel processes with arbitrary initial processor available time. Res Rep 1988.

[119] Lee C-Y, Danusaputro Liman S. Capacitated two-parallel machines scheduling to minimize sum of job completion times. Discrete Appl Math 1993;41:211-22. doi:10.1016/0166-218X(90)90055-H.

[120] Lee C-Y. Parallel machines scheduling with nonsimultaneous machine available time. Discrete Appl Math 1991;30:53-61. doi:10.1016/0166-218X(91)90013-M.

[121] McNaughton R. Scheduling with deadlines and loss functions. Manag Sci 1959;6:1-12.

[122] Schmidt G. Scheduling with limited machine availability. Eur J Oper Res 2000;121:115. doi:10.1016/S0377-2217(98)00367-1.

[123] Gao J, Gen M, Sun L. Scheduling jobs and maintenances in flexible job shop with a hybrid genetic algorithm. J Intell Manuf 2006;17:493-507. doi:10.1007/s10845-005-0021-x.

[124] Xiao L, Song S, Chen X, Coit DW. Joint optimization of production scheduling and machine group preventive maintenance. Reliab Eng Syst Saf 2016;146:68-78. doi:10.1016/j.ress.2015.10.013.

[125] Berrichi A, Yalaoui F, Amodeo L, Mezghiche M. Bi-Objective Ant Colony Optimization approach to optimize production and maintenance scheduling. Comput Oper Res 2010;37:1584-96. doi:10.1016/j.cor.2009.11.017.

[126] Upasani K, Bakshi M, Pandhare V, Lad BK. Distributed maintenance planning in manufacturing industries. Comput Ind Eng 2017;108:1-14. doi:10.1016/j.cie.2017.03.027.

[127] Kralj BL, Petrović R. Optimal preventive maintenance scheduling of thermal generating units in power systems -A survey of problem formulations and solution methods. Eur J Oper Res 1988;35:1-15. doi:10.1016/0377-2217(88)90374-8.

[128] Conejo AJ, García-Bertrand R, Díaz-Salazar M. Generation maintenance scheduling in restructured power systems. IEEE Trans Power Syst 2005;20:984-92. doi:10.1109/TPWRS.2005.846078.

[129] Perez-Canto S, Rubio-Romero JC. A model for the preventive maintenance scheduling of power plants including wind farms. Reliab Eng Syst Saf 2013;119:67-75. doi:10.1016/j.ress.2013.04.005.

[130] Dahal KP, Chakpitak N. Generator maintenance scheduling in power systems using metaheuristic-based hybrid approaches. Electr Power Syst Res 2007;77:771-9. doi:10.1016/j.epsr.2006.06.012.

[131] Ekpenyong UE, Zhang J, Xia X. An improved robust model for generator maintenance scheduling. Electr Power Syst Res 2012;92:29-36. doi:10.1016/j.epsr.2012.03.016. 
[132] Schlünz EB, Van Vuuren JH. An investigation into the effectiveness of simulated annealing as a solution approach for the generator maintenance scheduling problem. Int J Electr Power Energy Syst 2013;53:166-74. doi:10.1016/j.ijepes.2013.04.010.

[133] Dalgic Y, Lazakis I, Dinwoodie I, McMillan D, Revie M. Advanced logistics planning for offshore wind farm operation and maintenance activities. Ocean Eng 2015;101:211-26. doi:10.1016/j.oceaneng.2015.04.040.

[134] Zhang Z, Kusiak A, Song Z. Scheduling electric power production at a wind farm. Eur J Oper Res 2013;224:227-38. doi:10.1016/j.ejor.2012.07.043.

[135] Gundegjerde C, Halvorsen IB, Halvorsen-Weare EE, Hvattum LM, Nonås LM. A stochastic fleet size and mix model for maintenance operations at offshore wind farms. Transp Res Part C Emerg Technol 2015;52:74-92. doi:10.1016/j.trc.2015.01.005.

[136] Zhong S, Pantelous AA, Beer M, Zhou J. Constrained non-linear multi-objective optimisation of preventive maintenance scheduling for offshore wind farms. Mech Syst Signal Process 2018;104:347-69. doi:10.1016/j.ymssp.2017.10.035.

[137] Froger A, Gendreau M, Mendoza JE, Pinson É, Rousseau L-M. Maintenance scheduling in the electricity industry: A literature review. Eur J Oper Res 2016;251:695706. doi:10.1016/j.ejor.2015.08.045.

[138] Soh SS, Radzi NHM, Haron H. Review on scheduling techniques of preventive maintenance activities of railway, 2012, p. 310-5. doi:10.1109/CIMSim.2012.56.

[139] Mobley K, Higgins L, Wikoff D. Maintenance Engineering Handbook. McGraw-Hill Education; 2008.

[140] Parida A, Kumar U. Maintenance productivity and performance measurement. Handb. Maint. Manag. Eng., 2009, p. 17-41. doi:10.1007/978-1-84882-472-0_2.

[141] Milosavljević N, Teodorović D, Papić V, Pavković G. A fuzzy approach to the vehicle assignment problem. Transp Plan Technol 1996;20:33-47. doi:10.1080/03081069608717578.

[142] Papić V, Medar O, Pejčić Tarle S. Management of vehicle fleet maintenance in conditions of sustainable development. Mobil Veh Mech 1999;25:37-46.

[143] Li J-Q, Mirchandani PB, Borenstein D. Real-time vehicle rerouting problems with time windows. Eur J Oper Res 2009;194:711-27. doi:10.1016/j.ejor.2007.12.037.

[144] Vujanović D, Mijailović R, Momčilović V, Papić V. Energy efficiency as a criterion in the vehicle fleet management process. Therm Sci 2010;14:865-78. doi:10.2298/TSCI090719010V.

[145] Christensen P, Elvik R. Effects on accidents of periodic motor vehicle inspection in Norway. Accid Anal Prev 2007;39:47-52. doi:10.1016/j.aap.2006.06.003.

[146] Bin O. A logit analysis of vehicle emissions using inspection and maintenance testing data. Transp Res Part Transp Environ 2003;8:215-27. doi:10.1016/S1361-9209(03)00004-X.

[147] Vujanović D, Momčilović V, Bojović N, Papić V. Evaluation of vehicle fleet maintenance management indicators by application of DEMATEL and ANP. Expert Syst Appl 2012;39:10552-63. doi:10.1016/j.eswa.2012.02.159.

[148] Hu Q, Boylan JE, Chen H, Labib A. OR in spare parts management: A review. Eur J Oper Res 2018;266:395-414. doi:10.1016/j.ejor.2017.07.058.

[149] Bacchetti A, Saccani N. Spare parts classification and demand forecasting for stock control: Investigating the gap between research and practice. Omega 2012;40:722-37. doi:10.1016/j.omega.2011.06.008.

[150] Van Horenbeek A, Buré J, Cattrysse D, Pintelon L, Vansteenwegen P. Joint maintenance and inventory optimization systems: A review. Int J Prod Econ 2013;143:499_ 508. doi:10.1016/j.ijpe.2012.04.001. 
[151] Roda I, Macchi M, Fumagalli L, Viveros P. A review of multi-criteria classification of spare parts: From literature analysis to industrial evidences. J Manuf Technol Manag 2014;25:528-49. doi:10.1108/JMTM-04-2013-0038.

[152] Heragu SS, Gupta YP. A heuristic for designing cellular manufacturing facilities. Int J Prod Res 1994;32:125-40. doi:10.1080/00207549408956920.

[153] Chen M. A heuristic for solving manufacturing process and equipment selection problems. Int J Prod Res 1999;37:359-74. doi:10.1080/002075499191814.

[154] Dağdeviren M. Decision making in equipment selection: An integrated approach with AHP and PROMETHEE. J Intell Manuf 2008;19:397-406. doi:10.1007/s10845-008-0091-7.

[155] Azam M, Tu F, Pattipati K. Multi-phase Reliability Analysis of Complex Systems. vol. 5107, 2003, p. 27-43. doi:10.1117/12.488523.

[156] Sperstad IB, Stålhane M, Dinwoodie I, Endrerud O-EV, Martin R, Warner E. Testing the robustness of optimal access vessel fleet selection for operation and maintenance of offshore wind farms. Ocean Eng 2017;145:334-43. doi:10.1016/j.oceaneng.2017.09.009.

[157] Šelih J, Kne A, Srdić A, Žura M. Multiple-criteria decision support system in highway infrastructure management. Transport 2008;23:299-305. doi:10.3846/16484142.2008.23.299-305.

[158] Patidar V, Sinha KC, Labi S, Thompson PD. 2007.

[159] Patidar V, Labi S, Morin T, Thompson PD, Sinha KC. Evaluating methods and algorithms for multicriteria bridge management at the network level. 2011. doi:10.3141/2220-05.

[160] Johnson MB. Proj Prioritization Using Multiobjective Util Funct 2008:189-94.

[161] Bai Q, Labi S, Sinha KC, Thompson PD. Multiobjective optimization for project selection in network-level bridge management incorporating decision-maker's preference using the concept of holism. J Bridge Eng 2013;18:879-89. doi:10.1061/(ASCE)BE.19435592.0000428 .

[162] Kuhn KD. Network-level infrastructure management using approximate dynamic programming. J Infrastruct Syst 2010;16:103-11. doi:10.1061/(ASCE)IS.1943-555X.0000019.

[163] Santos J, Ferreira A, Flintsch G, Cerezo V. A multi-objective optimisation approach for sustainable pavement management. Struct Infrastruct Eng 2018;14:854-68. doi:10.1080/15732479.2018.1436571.

[164] Falls LC, Haas R, Tighe S. Asset service index as integration mechanism for civil infrastructure. 2006.

[165] Li Z, Sinha KC. Methodology for multicriteria decision making in highway asset management. 2004. doi:10.3141/1885-12.

[166] Durango-Cohen PL, Sarutipand P. Capturing interdependencies and heterogeneity in the management of multifacility transportation infrastructure systems. J Infrastruct Syst 2007;13:115-23. doi:10.1061/(ASCE)1076-0342(2007)13:2(115).

[167] Bai Q, Ahmed A, Li Z, Labi S. A hybrid pareto frontier generation method for tradeoff analysis in transportation asset management. Comput-Aided Civ Infrastruct Eng 2015;30:163-80. doi:10.1111/mice.12079.

[168] Sinha KC, Labi S, Agbelie BRDK. Transportation infrastructure asset management in the new millennium: continuing issues, and emerging challenges and opportunities. Transp Transp Sci 2017;13:591-606. doi:10.1080/23249935.2017.1308977.

[169] Moss TR, Woodhouse J. Criticality analysis revisited. Qual Reliab Eng Int 1999;15:11721. doi:10.1002/(SICI)1099-1638(199903/04)15:2<117::AID-QRE238>3.0.CO;2-I. 
[170] Pelaez CE, Bowles JB. Using fuzzy logic for system criticality analysis. Proc IEEE Annu Reliab Maintainab Symp 1994:449-55.

[171] Pillay A, Wang J. Modified failure mode and effects analysis using approximate reasoning. Reliab Eng Syst Saf 2003;79:69-85. doi:10.1016/S0951-8320(02)00179-5.

[172] Crespo Márquez A, Moreu De Leõn P, Sola Rosique A, Gõmez Fernández JF. Criticality Analysis for Maintenance Purposes: A Study for Complex In-service Engineering Assets. Qual Reliab Eng Int 2016;32:519-33. doi:10.1002/qre.1769.

[173] Adams J, Srinivasan R, Parlikad AK, González-Prida V, Crespo AM. Towards Dynamic Criticality-Based Maintenance Strategy for Industrial Assets. IFAC-Pap 2016;49:103-7. doi:10.1016/j.ifacol.2016.11.018.

[174] Rausand M. Reliability centered maintenance. Reliab Eng Syst Saf 1998;60:121-32. doi:10.1016/S0951-8320(98)83005-6.

[175] Selvik JT, Aven T. A framework for reliability and risk centered maintenance. Reliab Eng Syst Saf 2011;96:324-31. doi:10.1016/j.ress.2010.08.001.

[176] Gómez De León Hijes FC, Cartagena JJR. Maintenance strategy based on a multicriterion classification of equipments. Reliab Eng Syst Saf 2006;91:444-51. doi:10.1016/j.ress.2005.03.001.

[177] Guo L, Gao J, Yang J, Kang J. Criticality evaluation of petrochemical equipment based on fuzzy comprehensive evaluation and a BP neural network. J Loss Prev Process Ind 2009;22:469-76. doi:10.1016/j.jlp.2009.03.003.

[178] Marhaug A, Barabadi A, Stagrum E, Karlsen K, Olsen A, Ayele YZ. Criticality analysis for maintenance purposes of platform supply vessels in remote areas. J Offshore Mech Arct Eng 2017;139. doi:10.1115/1.4035304.

[179] Crespo Márquez A. The maintenance management framework. Maint Manag Framew Models Methods Complex Syst Maint 2007.

[180] Chan WT, Fwa TF, Tan JY. Optimal fund-allocation analysis for multidistrict highway agencies. J Infrastruct Syst 2003;9:167-75. doi:10.1061/(ASCE)1076-0342(2003)9:4(167).

[181] Nishijima K, Faber M. A budget management approach for societal infrastructure projects. Struct Infrastruct Eng 2009;5:41-7. doi:10.1080/15732470701322792.

[182] Fwa TF, Farhan J. Optimal multiasset maintenance budget allocation in highway asset management. J Transp Eng 2012;138:1179-87. doi:10.1061/(ASCE)TE.1943-5436.0000414.

[183] Gharaibeh NG, Chiu Y-C, Gurian PL. Decision methodology for allocating funds across transportation infrastructure assets. J Infrastruct Syst 2006;12:1-9. doi:10.1061/(ASCE)1076-0342(2006)12:1(1).

[184] Mild P, Salo A. Combining a multiattribute value function with an optimization model: An application to dynamic resource allocation for infrastructure maintenance. Decis Anal 2009;6:139-52.

[185] Dehghani M, Giustozzi F, Flintsch G, Crispino M. Cross-asset resource allocation framework for achieving performance sustainability. 2013. doi:10.3141/2361-03.

[186] Roshandeh AM, Li Z, Neishapouri M, Patel H, Liu Y. Trade-off analysis approach for multiobjective transportation investment decision making. J Transp Eng 2015;141. doi:10.1061/(ASCE)TE.1943-5436.0000747.

[187] Truong T, Li Z, Kepaptsoglou K. Entropy-STEP multiobjective trade-off analysis method for optimal transportation investment decisions. J Transp Eng Part Syst 2018;144. doi:10.1061/JTEPBS.0000100.

[188] Yang X-S. Engineering optimization an introduction with metaheuristic applications. Hoboken, N.J.: Hoboken, N.J. : John Wiley, c2010.; 2010. 
[189] Yao X, Fernández-Gaucherand E, Fu MC, Marcus SI. Optimal preventive maintenance scheduling in semiconductor manufacturing. IEEE Trans Semicond Manuf 2004;17:34556. doi:10.1109/TSM.2004.831948.

[190] Ramírez-Hernández JA, Crabtree J, Yao X, Fernandez E, Fu MC, Janakiram M, et al. Optimal preventive maintenance scheduling in semiconductor manufacturing systems: Software tool and simulation case studies. IEEE Trans Semicond Manuf 2010;23:477-89. doi:10.1109/TSM.2010.2051731.

[191] Topal E, Ramazan S. A new MIP model for mine equipment scheduling by minimizing maintenance cost. Eur J Oper Res 2010;207:1065-71. doi:10.1016/j.ejor.2010.05.037.

[192] Edwin KW, Curtius F. New maintenance-scheduling method with production cost minimization via integer linear programming. Int J Electr Power Energy Syst 1990;12:16570. doi:10.1016/0142-0615(90)90029-B.

[193] Da Silva EL, Schilling MT, Rafael MC. Generation maintenance scheduling considering transmission constraints. IEEE Trans Power Syst 2000;15:838-43. doi:10.1109/59.867182.

[194] H. Barot, K. Bhattacharya. Security Coordinated Maintenance Scheduling in Deregulation Based on Genco Contribution to Unserved Energy. IEEE Trans Power Syst 2008;23:1871-82. doi:10.1109/TPWRS.2008.2002296.

[195] Chattopadhyay D. A practical maintenance scheduling program: mathematical model and case study. IEEE Trans Power Syst 1998;13:1475-80. doi:10.1109/59.736293.

[196] Schlünz EB, van Vuuren JH. The application of a computerised decision support system for generator maintenance scheduling: A South African case study. South Afr J Ind Eng 2012;23:169-79.

[197] Jacobs TL. Optimal long-term scheduling of bridge deck replacement and rehabilitation. J Transp Eng 1992;118:312-22. doi:10.1061/(ASCE)0733947X(1992)118:2(312).

[198] Ravirala V, Grivas DA, Madan A, Schultz BC. Multicriteria optimization method for network-level bridge management. Transp Res Rec 1996:37-43. doi:10.3141/1561-05.

[199] Wang F, Zhang Z, Machemehl RB. Decision-making problem for managing pavement maintenance and rehabilitation projects. Decis-Mak Probl Manag Pavement Maint Rehabil Proj 2003:21-8.

[200] Wong CS, Chan FTS, Chung SH. A joint production scheduling approach considering multiple resources and preventive maintenance tasks. Int J Prod Res 2013;51:883-96. doi:10.1080/00207543.2012.677070.

[201] Yang Z, Djurdjanovic D, Ni J. Maintenance scheduling in manufacturing systems based on predicted machine degradation. J Intell Manuf 2008;19:87-98. doi:10.1007/s10845-007-0047-3.

[202] Ahire S, Greenwood G, Gupta A, Terwilliger M. Workforce-constrained preventive maintenance scheduling using evolution strategies. Decis Sci 2000;31:833-56.

[203] Deris S, Omatu S, Ohta H, Shaharudin Kutar LC, Abd Samat P. Ship maintenance scheduling by genetic algorithm and constraint-based reasoning. Eur J Oper Res 1999;112:489-502. doi:10.1016/S0377-2217(97)00399-8.

[204] Chen L, Aihara K. Chaotic simulated annealing by a neural network model with transient chaos. Neural Netw 1995;8:915-30. doi:10.1016/0893-6080(95)00033-V.

[205] Satoh T, Nara K. Maintenance Scheduling By Using Simulated Annealing Method. IEEE Trans Power Syst 1991;6:850-7. doi:10.1109/59.76735. 
[206] Burke EK, Smith AJ. Hybrid evolutionary techniques for the maintenance scheduling problem. IEEE Trans Power Syst 2000;15:122-8. doi:10.1109/59.852110.

[207] Wang Y, Handschin E. New genetic algorithm for preventive unit maintenance scheduling of power systems. Int J Electr Power Energy Syst 2000;22:343-8. doi:10.1016/S0142-0615(99)00062-9.

[208] Koay CA, Srinivasan D. Particle swarm optimization-based approach for generator maintenance scheduling, 2003, p. 167-73. doi:10.1109/SIS.2003.1202263.

[209] Yare Y, Venayagamoorthy GK. Optimal maintenance scheduling of generators using multiple swarms-MDPSO framework. Eng Appl Artif Intell 2010;23:895-910. doi:10.1016/j.engappai.2010.05.006.

[210] Saraiva JT, Pereira ML, Mendes VT, Sousa JC. A Simulated Annealing based approach to solve the generator maintenance scheduling problem. Electr Power Syst Res 2011;81:1283-91. doi:10.1016/j.epsr.2011.01.013.

[211] El-Amin I, Duffuaa S, Abbas M. Tabu search algorithm for maintenance scheduling of generating units. Electr Power Syst Res 2000;54:91-9. doi:10.1016/S0378-7796(99)00079-6.

[212] Kim H, Hayashi Y, Nara K. An algorithm for thermal unit maintenance scheduling through combined use of ga sa and ts. IEEE Trans Power Syst 1997;12:329-35. doi:10.1109/59.574955.

[213] Leou R-C. A new method for unit maintenance scheduling considering reliability and operation expense. Int J Electr Power Energy Syst 2006;28:471-81. doi:10.1016/j.ijepes.2006.02.009.

[214] Petchrompo S, Parlikad AK. Heuristic optimisation for multi-asset intervention planning in a petrochemical plant, United Kingdom: 2018.

[215] Gan S, Zhang Z, Zhou Y, Shi J. Joint optimization of maintenance, buffer, and spare parts for a production system. Appl Math Model 2015;39:6032-42. doi:10.1016/j.apm.2015.01.035.

[216] Rausch M, Liao H. Joint production and spare part inventory control strategy driven by condition based maintenance. IEEE Trans Reliab 2010;59:507-16. doi:10.1109/TR.2010.2055917.

[217] Ilgin MA, Tunali S. Joint optimization of spare parts inventory and maintenance policies using genetic algorithms. Int J Adv Manuf Technol 2007;34:594-604. doi:10.1007/s00170-006-0618-z.

[218] Xie J, Wang H. Joint optimization of condition-based preventive maintenance and spare ordering policy, 2008. doi:10.1109/WiCom.2008.1468.

[219] Marseguerra M, Zio E, Podofillini L. Multiobjective spare part allocation by means of genetic algorithms and Monte Carlo simulation. Reliab Eng Syst Saf 2005;87:325-35. doi:10.1016/j.ress.2004.06.002.

[220] Pilson C, Hudson WR, Anderson V. Multiobjective optimization in pavement management by using genetic algorithms and efficient surfaces. 1998.

[221] Peng F, Kang S, Li X, Ouyang Y, Somani K, Acharya D. A Heuristic Approach to the Railroad Track Maintenance Scheduling Problem. Comput-Aided Civ Infrastruct Eng 2011;26:129-45. doi:10.1111/j.1467-8667.2010.00670.x.

[222] Budai G, Huisman D, Dekker R. Scheduling preventive railway maintenance activities. J Oper Res Soc 2006;57:1035-44. doi:10.1057/palgrave.jors.2602085.

[223] Wang S, Liu M. Multi-objective optimization of parallel machine scheduling integrated with multi-resources preventive maintenance planning. J Manuf Syst 2015;37:182-92. doi:10.1016/j.jmsy.2015.07.002. 
[224] Barán B, Von Lücken C, Sotelo A. Multi-objective pump scheduling optimisation using evolutionary strategies. Adv Eng Softw 2005;36:39-47. doi:10.1016/j.advengsoft.2004.03.012.

[225] Zhang D, Li W, Xiong X. Bidding based generator maintenance scheduling with tripleobjective optimization. Electr Power Syst Res 2012;93:127-34. doi:10.1016/j.epsr.2012.07.014.

[226] Verma AK, Srividya A, Rana A, Khattri SK. Optimization of maintenance scheduling of ship borne machinery for improved reliability and reduced cost. Int J Reliab Qual Saf Eng 2012;19. doi:10.1142/S0218539312500143.

[227] Bocchini P, Frangopol DM. A probabilistic computational framework for bridge network optimal maintenance scheduling. Reliab Eng Syst Saf 2011;96:332-49. doi:10.1016/j.ress.2010.09.001.

[228] Liu Min, Frangopol Dan M. Multiobjective Maintenance Planning Optimization for Deteriorating Bridges Considering Condition, Safety, and Life-Cycle Cost. J Struct Eng 2005;131:833-42. doi:10.1061/(ASCE)0733-9445(2005)131:5(833).

[229] Miyamoto Ayaho, Kawamura Kei, Nakamura Hideaki. Bridge Management System and Maintenance Optimization for Existing Bridges. Comput-Aided Civ Infrastruct Eng 2002;15:45-55. doi:10.1111/0885-9507.00170.

[230] Neves Luís A. C., Frangopol Dan M., Petcherdchoo Aruz. Probabilistic LifetimeOriented Multiobjective Optimization of Bridge Maintenance: Combination of Maintenance Types. J Struct Eng 2006;132:1821-34. doi:10.1061/(ASCE)07339445(2006)132:11(1821).

[231] Morcous G. Pareto Analysis for Multicriteria Optimization of Bridge Preservation Decisions. Transp Res Rec J Transp Res Board 2007;1991:62-8. doi:10.3141/1991-08.

[232] Fwa T. F., Chan W. T., Hoque K. Z. Multiobjective Optimization for Pavement Maintenance Programming. J Transp Eng 2000;126:367-74. doi:10.1061/(ASCE)0733947X(2000)126:5(367).

[233] Wang KCP, Nguyen V, Zaniewski JP. Genetic Algorithms-Based Network Optimization System with Multiple Objectives. Transp Res Rec 2007;2016:85-95. doi:10.3141/2016-10.

[234] Holland JH. Genetic algorithms. Sci Am 1992;267:66-72. doi:10.1038/scientificamerican0792-66.

[235] Kirkpatrick S, Gelatt Jr. CD, Vecchi MP. Optimization by simulated annealing. Science 1983;220:671-80. doi:10.1126/science.220.4598.671.

[236] Kennedy J, Eberhart R. Particle swarm optimization. vol. 4, 1995, p. 1942-8.

[237] Glover F. Future paths for integer programming and links to artificial intelligence. Comput Oper Res 1986;13:533-49. doi:10.1016/0305-0548(86)90048-1.

[238] Wu Z, Flintsch G, Ferreira A, de Picado-Santos L. Framework for multiobjective optimization of physical highway assets investments. J Transp Eng 2012;138:1411-21. doi:10.1061/(ASCE)TE.1943-5436.0000458.

[239] Van Veldhuizen DA, Lamont GB. Multiobjective evolutionary algorithms: analyzing the state-of-the-art. Evol Comput 2000;8:125-47.

[240] Schaffer JD. Multiple objective optimization with vector evaluated genetic algorithms. Proc First Int Conf Genet Algorithms 1985:93-100.

[241] Fonseca CM, Fleming PJ. Genetic algorithms for multiobjective optimization: Formulation, discussion and generalization. Proc Fifth Int Conf Genet Algorithms 1993:416-23. 
[242] Deb K, Agrawal S, Pratap A, Meyarivan T. A fast elitist non-dominated sorting genetic algorithm for multi-objective optimization: NSGA-II. Lect Notes Comput Sci Subser Lect Notes Artif Intell Lect Notes Bioinforma 2000;1917:849-58.

[243] Zitzler E, Thiele L. An evolutionary algorithm for multiobjective optimization: The strength Pareto approach. Tech Rep 1998;43.

[244] Zitzler E, Laumanns M, Thiele L. SPEA2: Improving the strength pareto evolutionary algorithm. Tech Rep 2001;103.

[245] Bui LT, Essam D, Abbass HA, Green D. Performance analysis of evolutionary multiobjective optimization methods in noisy environments. Complex Int 2005;11:29-39.

[246] Gajpal PP, Ganesh LS, Rajendran C. Criticality analysis of spare parts using the analytic hierarchy process. Int J Prod Econ 1994;35:293-7. doi:10.1016/0925-5273(94)900957.

[247] Braglia M, Grassi A, Montanari R. Multi-attribute classification method for spare parts inventory management. J Qual Maint Eng 2004;10:55-65. doi:10.1108/13552510410526875.

[248] Molenaers A, Baets H, Pintelon L, Waeyenbergh G. Criticality classification of spare parts: A case study. Int J Prod Econ 2012;140:570-8. doi:10.1016/j.ijpe.2011.08.013.

[249] Zeng Y-R, Wang L, He J. A novel approach for evaluating control criticality of spare parts using fuzzy comprehensive evaluation and GRA. Int J Fuzzy Syst 2012;14:392-401.

[250] Sinha KC, Patidar V, Li Z, Labi S, Thompson PD. Establishing the weights of performance criteria: Case studies in transportation facility management. J Transp Eng 2009;135:619-31. doi:10.1061/(ASCE)TE.1943-5436.0000039.

[251] Gabriel SA, Ordóñez JF, Faria JA. Contingency planning in project selection using multiobjective optimization and chance constraints. J Infrastruct Syst 2006;12:112-20. doi:10.1061/(ASCE)1076-0342(2006)12:2(112).

[252] Braglia M. MAFMA: Multi-attribute failure mode analysis. Int J Qual Reliab Manag 2000;17:1017-33. doi:10.1108/02656710010353885.

[253] Braglia M, Bevilacqua M. Fuzzy modelling and analytical hierarchy processing as a means of quantifying risk levels associated with failure modes in production systems. Technol Law Insur 2000;5:125-34. doi:10.1080/135993700750364341.

[254] Braglia Marcello, Frosolini Marco, Montanari Roberto. Fuzzy TOPSIS approach for failure mode, effects and criticality analysis. Qual Reliab Eng Int 2003;19:425-43. doi:10.1002/qre.528.

[255] Guimarães ACF, Lapa CMF. Fuzzy inference to risk assessment on nuclear engineering systems. Appl Soft Comput 2007;7:17-28. doi:10.1016/j.asoc.2005.06.002.

[256] Sandra AK, Vinayaka Rao VR, Raju KS, Sarkar AK. Prioritization of pavement stretches using fuzzy MCDM approach - A case study. vol. 39. 2007. doi:10.1007/978-3540-70706-6_25.

[257] Ramadhan RH, Al-Abdul Wahhab HI, Duffuaa SO. Use of an analytical hierarchy process in pavement maintenance priority ranking. J Qual Maint Eng 1999;5:25-39. doi:10.1108/13552519910257041.

[258] Odoki JB, Di Graziano A, Akena R. A multi-criteria methodology for optimising road investments. Proc Inst Civ Eng Transp 2015;168:34-47. doi:10.1680/tran.12.00053.

[259] Cafiso S, Di Graziano A, Kerali HR, Odoki JB. Multicriteria analysis method for pavement maintenance management. 2002. doi:10.3141/1816-09.

[260] Ravirala V, Grivas DA. Goal-programming methodology for integrating pavement and bridge programs. J Transp Eng 1995;121:345-51. doi:10.1061/(ASCE)0733947X(1995)121:4(345). 
[261] Bevilacqua Maurizio, Braglia Marcello, Gabbrielli Roberto. Monte Carlo simulation approach for a modified FMECA in a power plant. Qual Reliab Eng Int 2000;16:313-24. doi:10.1002/1099-1638(200007/08)16:4<313::AID-QRE434>3.0.CO;2-U.

[262] Chowdhury M, Tan P. Investment Analysis Using the Constraint Multiobjective Programming Method: A Case Study. Transp Res Rec J Transp Res Board 2005;1924:2312. doi:10.3141/1924-29.

[263] Chowdhury MA, Garber NJ, Li D. Multiobjective methodology for highway safety resource allocation. J Infrastruct Syst 2000;6:138-44. doi:10.1061/(ASCE)10760342(2000)6:4(138).

[264] Sadek AW, Kvasnak A, Segale J. Integrated infrastructure management systems: Small urban area's experience. J Infrastruct Syst 2003;9:98-106. doi:10.1061/(ASCE)10760342(2003)9:3(98).

[265] Saaty TL. How to make a decision: The analytic hierarchy process. Eur J Oper Res 1990;48:9-26. doi:10.1016/0377-2217(90)90057-I.

[266] BELLMAN RE, ZADEH LA. DECISION-MAKING IN A FUZZY ENVIRONMENT. Manag Sci 1970;17:b-141-64.

[267] Charnes A, Cooper WW. Goal programming and multiple objective optimizations: Part 1. Eur J Oper Res 1977;1:39-54. doi:10.1016/S0377-2217(77)81007-2.

[268] HAIMES YV, LASDON LS, WISMER DA. On a bicriterion formation of the problems of integrated system identification and system optimization. IEEE Trans Syst Man Cybern 1971;SMC-1:296-7. doi:10.1109/TSMC.1971.4308298.

[269] Mavrotas G. Effective implementation of the $\varepsilon$-constraint method in Multi-Objective Mathematical Programming problems. Appl Math Comput 2009;213:455-65. doi:10.1016/j.amc.2009.03.037.

[270] Wallenius J, Dyer JS, Fishburn PC, Steuer RE, Zionts S, Deb K. Multiple criteria decision making, multiattribute utility theory: Recent accomplishments and what lies ahead. Manag Sci 2008;54:1336-49. doi:10.1287/mnsc.1070.0838. 